\title{
La Integración Supranacional y su Impacto en Estados con Estructura Compleja
}

Victor Bazán

Profesor Titular Efectivo de las asignaturas Derecho Constitucional y Derecho Internacional Público de la Faculrad de Derecho y Ciencias Sociales de la Universidad Católica de Cuyo, San Juan, Argentina. Fundador y actual Director del Instituto de Derecho Constitucional, Procesal Constitucional y Derechos Humanos de la misma Facultad. Magistrado de la Camara de Apelaciones de Paz Letrada de San Juan.

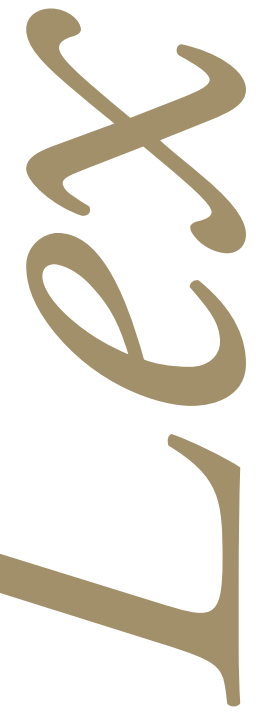




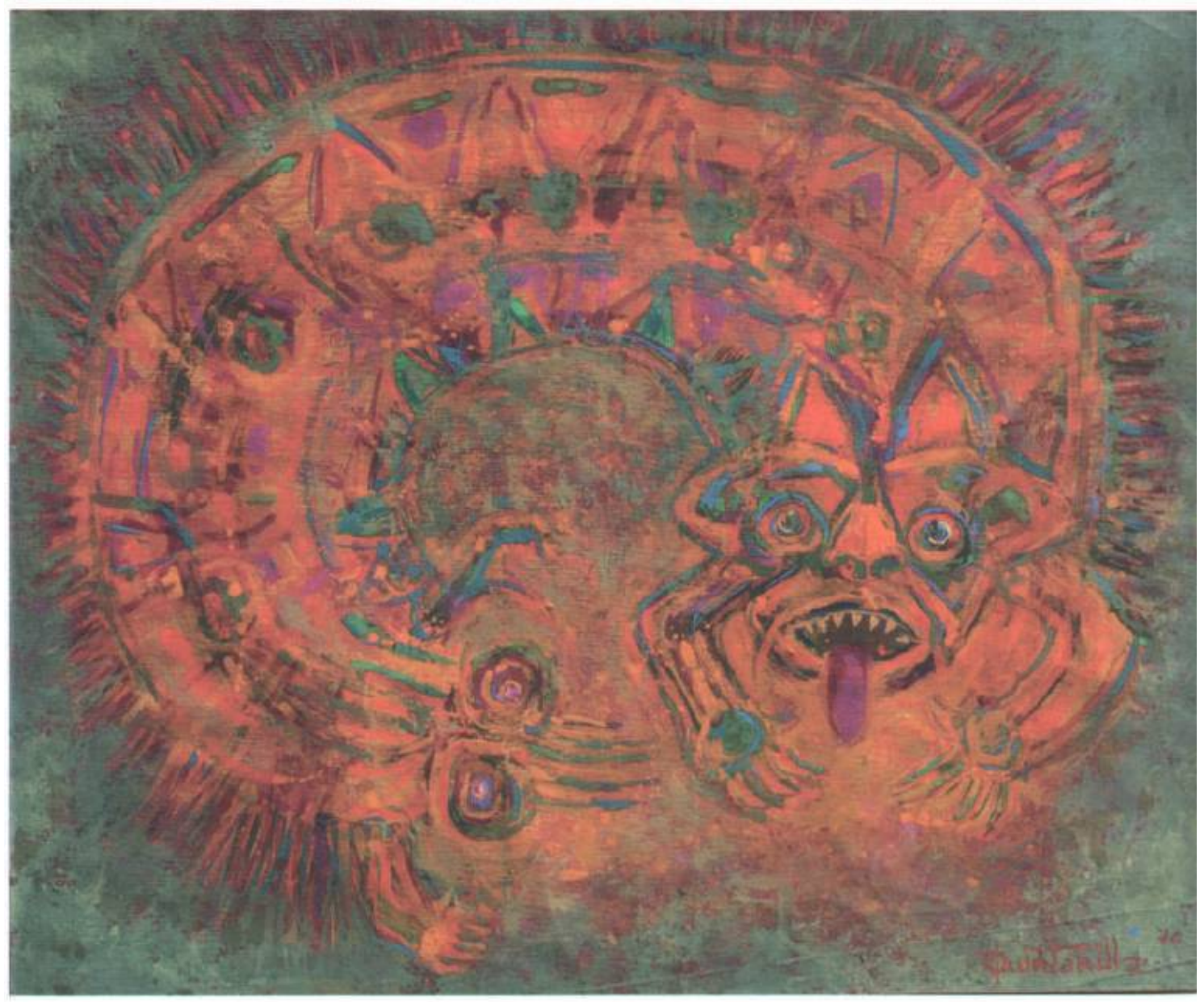

Inauditos rezagos. Técnica mixta, $1970(37 \mathrm{~cm} . \times 44.5 \mathrm{~cm}$.) 
I. Consideraciones previas. II. Anotaciones contextuales adicionales. III. Los Estados partes del mercosur, ¿están constitucional y/o jurisprudencialmente preparados para avanzar hacia formas integrativas más intensas?: 1. Planteo del problema. 2. Repaso iuscomparativo: A) Argentina y Paraguay. B) Brasil y Uruguay. C) Venezuela. D) Balance. IV. Ciertas cuestiones conflictivas que surgen de la interrelación de la integración supranacional y el federalismo y de la búsqueda de instancias de participación de los entes subestatales: 1. Perfiles de la cuestión. 2. El caso argentino: a) La Regionalización. b) La actividad internacional de las provincias. c) ¿Una protección adicional para el federalismo en los procesos de integración? d) ¿Y los municipios? 3. La experiencia europea: a) Participación de las colectividades territoriales en el proceso comunitario. b) Responsabilidad internacional del Estado por acciones y omisiones de las entidades infraestatales. V. Acerca de determinadas instancias de vinculación y participación de las entidades infraestatales en la experiencia comunitaria europea: 1 . El comité de las regiones: a) Génesis. b) Composición y naturaleza del comité. Los principios de subsidiariedad y proporcionalidad. c) El tratado de Lisboa, el comité de las regiones, la cohesión territorial y las autonomias regionales y locales. d) Sucinto balance del accionar del comité. Prospectiva. 2. Eurocities. VI. Alternativas de participación de los entes subestatales en el proceso integrativo mercosureño: 1. Sobre el Parlamento del MERCOSUR. 2. El Foro Consultivo de Municipios, Estados Federados, Provincias y Departamentos del MERCOSUR. 3. Mercociudades. VII. Esquema de conclusiones.

\section{CONSIDERACIONES PREVIAS}

Es obvio que nada se descubre al recordar que la irrupción de nuevos espacios integrados plantea, correlativamente, renovados desafios, fundamentalmente en los esquemas estaduales de estructura territorial compleja. 
De su lado, cabe advertir que el federalismo es un proceso dinámico y con numerosas fórmulas posibles de configuración. Tanto, que es ya clásica la afirmación de FriedRicH en cuanto a que existen tantos federalismos como Estados federales con sus múltiples variantes!.

Se impone aqui un interrogante inicial: ¿Existe incompatibilidad entre el establecimiento de bloques supranacionales, que supone un movimiento de centralización, y el federalismo intraestatal, que por esencia contiene una fuerte nota de descentralización política?

La respuesta es, a nuestro criterio, negativa. No cabria predicar a priori semejante contradicción. Antes bien, lo deseable sería generar una saludable relación de complementación entre integración (estructura comunitaria) y autonomía (federalismo u otros procesos de desconcentración politica) a partir de claras normas contenidas en la Ley Fundamental de que se trate, que permitan al Estado Nacional involucrarse en procesos integrativos preservando la pluralidad y las pautas de descentralización ad intra.

Presentado asi en breves pinceladas el problema central que aqui nos preocupa, daremos continuidad al trabajo enfocando sumariamente algunos aspectos contextuales complementarios para ahondar en la problemática a la que se refieren el interrogante en torno a la compatibilidad o incompatibilidad entre la integración supranacional y el modelo estadual federal (o con acentuados rasgos centrifugos) y la respuesta que arriesgábamos precedentemente.

Enseguida, formularemos un breve repaso iuscomparativo para verificar si los paises que originariamente suscribieron el Tratado de Asunción ${ }^{2}$ (constitutivo del Mercosur) se encuentran preparados desde el plano de sus respectivas Constituciones y de la jurisprudencia de sus correspondientes órganos de cierre de la jurisdicción constitucional, para avanzar hacia etapas más intensas y comprometidas en el proceso de integración, que supongan la efectiva transferencia (cesión, atribución, delegación, traspaso, etc.) de funciones hacia instituciones supranacionales para generar un escenario del que se desprenda derecho comunitario con sus características de autonomia, efecto directo y aplicación preferente en los Estados Miembros. Además, y aunque no se trate de un socio primigenio, la situación que frente al Mercosur ha asumido Venezuela nos lleva también a realizar -en mirada prospectiva- una alusión a la previsión constitucional de tal pais en el punto examinado.

Luego focalizaremos determinadas cuestiones delicadas que surgen de la interrelación de la integración supranacional y el federalismo y la importancia de buscar alternativas de partici-

1 Friensich, Carl, Teoria y realidad de la organización constitucional democrática, Ciudad: Fondo de Cultura Económica, 1946, p. 207.

2 El Tratado de Asunción fue suscripto el 26 de marzo de 1991 por la República Argentina, la República Federativa de Brasil, la República del Paraguay y la República Oriental del Uruguay. 
pación en aquélla por parte de los entes subestatales. Por cierto, no estarán ausentes algunas respuestas surgidas de la praxis europea, tomada como matriz referencial y potencial fuente de la que abrevar para extraer enseñanzas, pues este modelo comunitario (con más de cinco décadas de desarrollo) aunque con marcadas diferencias respecto del sistema del Mercosur, puede proporcionar cierta materia prima para capitalizar y extrapolar a este esquema integrativo (o al menos tener en cuenta como posibilidades de lege ferenda), aplicandose a Brasil, Argentina y Venezuela ${ }^{3}$, paises que -con sus respectivas particularidades- han adoptado modalidades de estructuración estadual federal.

A continuación, pasaremos revista a algunas de las instancias que en el mareo europeo existen para la protección de los intereses de las entidades infraestatales frente al proceso comunitario, esfera en la que principal pero no exclusivamente enfocaremos al Comité de las Regiones. De inmediato examinaremos ciertas perspectivas de vinculación y participación que se abren en la órbita del Mercosur para Estados, provincias, regiones, municipios y ciudades, de acuerdo con la nomenclatura que en la Ley Fundamental de cada enclave federal se escoja.

A su tiempo, el epilogo vendrả de la mano de las apreciaciones recapitulativas que se añadi. rán a las consideraciones conclusivas intercaladas en el nudo del trabajo.

\section{ANOTACIONES CONTEXTUALES ADICIONALES}

En relación con el sector temático delimitado por el interrogante que proponiamos al inicio de esta contribución y la respuesta que anticipábamos (en torno a la inexistencia de incompatibilidad de la integración supranacional y el federalismo o la descentralización intraestatales), ROLlA puntualiza, mutatis mutandi, que "el derecho comparado muestra cómo el empuje de la descentralización no alimenta las tendencias centrifugas o particularistas en las experiencias donde el sistema constitucional es capaz de identificar y codificar los valores en torno a los cuales todos los sujetos del pluralismo se reconocen" ${ }^{\text {". }}$.

5. La versión del federalismo venezolano de la Constitución de 1999 (uno de cuyos puntos oscuros fue viabilizar la desaparición del Senado) quedaba más debilitada aún en el frustrado texto de la nueva Constitución que propiciaba el presidente Hugo CHAvEz, aprobado el 2 de noviembre de 2007 por la Asamblea Nacional y que, en definitiva, fuera rechazado por el pueblo en el referendum de 2 de diciembre del mis. mo año.

4 Rolla, Giancarlo, "La descentralización en Italia. Un dificil equilibrio entre autonomia y unidad", en Hernandez (h.), Antonio M. (Director), La descentralización del poder en el Estado contemporáneo, Cordoba: Asociación Argentina de Derecho Constitucional, Instituto Italiano de Cultura de Cordoba e Instituro de Derecho Constitucional y Derecho Público Provincial y Municipal de la Facultad de Derecho y Ciencias Sociales de la Universidad Nacional de Córdoba, 2005, p. 44. 
El problema no es precisamente reciente. Por el contrario, con frecuencia cobra renovado impulso ya que aparecen cuestiones conflictivas nuevas o se reinventan aristas de otras que parecian ya solventadas y superadas.

De hecho, basta con reparar que de los cuatro socios originarios del Mercosur (Argentina, Brasil, Paraguay y Uruguay), nada más y nada menos que los dos primeros (los más fuertes y poderosos de aquel cuarteto inicial) presentan, con sus respectivas particularidades, una conformación estadual federal, al igual que Venezuela, que pretende insertarse en dicho esquema integrativo sudamericano como miembro pleno 6 .

Otro tanto ocurre en la experiencia europea, en la que -según la acertada percepción de ROLLA- cuando se realizó el acto institutivo de las comunidades económicas solo uno de los Estados fundadores tenia una estructura de base federal o regional (Alemania), mientras que en la actualidad se observa la existencia de diversos Estados regionalizados (Alemania, España, Bélgica, Italia y Austria), o bien procesos de descentralización al interior de ordenamientos tradicionalmente unitarios (Reino Unido y Francia)?

Entre un cúmulo de aspectos relevantes y, por cierto, conflictivos, pueden destacarse ejemplificativamente dos: por una parte, el impacto que la integración puede provocar en las regiones, provincias, comunidades autónomas, etc.; y, por otra, el modo en que estos entes podrían participar en los procesos de decisión de la estructura comunitaria, tema catalogado como "ineludible" por el autor citado en último término, quien añade que tal problemática necesita de procedimientos adecuados de colaboración entre los diversos niveles institucionales que componen el ordenamiento nacionals.

En el ámbito interno, la plataforma legitimante de tal relación de colaboración es un esquema de federalismo de concertación (o convergencia) y participativo, que permita una vincula-

5 La cuestión nos interesa y preocupa desde hace bastante tiempo, incluso antes de la reforma constitucional de 1994. Al respecto, ver BAZÁN, Victor, "Las provincias desde la perspectiva de la integración regional", en Bazín, Victor y Sanchez, Alberto (compiladores), Integración regional: Perspectivas para Latinoamérica, San Juan: Edit. Fundación Universitaria, 1994, pp. 205/218.

6. En 2004 Venezuela comenzó a transitar su camino en el Mercosur por medio del Acuerdo de Complementación Económica Mercosur - Colombia, Ecuador y Venezuela.

Por su parte, el 4 de julio de 2006 se suscribió en Caracas el Protocolo de Adhesión de la República Bolivariana de Venezuela al Mercosur, el que hasta el momento (finales de 2007) y según la información que pudimos recalar, sólo Argentina y Uruguay han ratificado. El art. 12 de dicho Protocolo lo cataloga como "instrumento adicional al Tratado de Asunción" y determina que entrará en vigencia el trigésimo día contado a partir de la fecha de depósito del quinto instrumento de ratificación.

7 RoLlA, Giancarlo, op. cit., pp. 41/42.

8 lbid., p. 42. 
ción equilibrada entre las instancias que forman la estructura federal y viabilice una alternativa de desarrollo y crecimiento integrado ad intra y ad extra.

Paralelamente, tal paradigma equilibrado deberá trasladarse al sistema comunitario y su cuadro de distribución y ejercicio de competencias con cada uno de los Estados Miembros, respetando las pautas de atribución, subsidiariedad, proporcionalidad y necesidad, sobre las que volveremos.

A propósito de todo ello, en la praxis comunitaria europea -que, como anticipábamos, pese a las claras diferencias con el Mercosur es el contexto del que se debe abrevar para extraer algunas enseñanzas que quizá resulten prospectivamente extrapolables, no sin beneficio de inventario, a nuestro modelo integrativo-, se ha reclamado la necesidad de dar coherencia a la participación regional en el proceso de integración europea, por medio de la institucionalización de un diảlogo en dos frentes: el comunitario, permitiendo a las regiones comunicarse con las instituciones de la Unión Europea (en adelante, también UE); y el interno del Estado, suscitando una colaboración entre las autoridades centrales y las autoridades regionales en relación con dicho proceso ${ }^{9}$.

Naturalmente la cuestión se comprende a partir del resultado de lo que se ha explicado como la reconducción del concepto clásico de "política exterior", separando el "núcleo duro" (cuya diagramación compete al Estado), de un conjunto de acciones que giran en su derredor, de "relieve internacional" o de "promoción exterior", consecuencia del proceso de globalización o internacionalización, y cuya realización puede y debe ser llevada a cabo por las entidades subestatales bajo el principio liminar de la "lealtad constitucional"10; tema que también retomaremos.

\section{III. ¿LOS ESTADOS PARTES DEL MERCOSUR ESTÁN CONSTITUCIONAL Y/O JURISPRUDENCIALMENTE PREPARADOS PARA AVANZAR HACIA FORMAS IN- TEGRATIVAS MÁS INTENSAS?}

\section{Planteo del problema}

Buceando en la dimensión constitucional del proceso de integración mercosureño, y partiendo del supuesto que el objetivo final de éste es la creación de un mercado común fo de un

9 Cfr. Perez Gonzalez, Manuel, "Facultades de los entes subnacionales en el sistema comunitario europeo", en DRNAS de Clément, Zlata y REy CARo, Ernesto J. (Directores), Jomadas de reflexión sobre regionalización y Mercosur, Córdoba: Marcos Lerner Editora, 2000, pp. 18/19.

10 Cfr., mutatis mutandi, Leguiva, Joaquin, "Intervención de apertura", en AA.VV., "La acción exterior y comunitaria de los Länder, regiones, cantones y comunidades autónomas", Vol. I, Bilbao: Universidad Carlos III de Madrid y Universidad del Pais Vasco, Instituto Vasco de Administración Pública, 1994, p. 16. 
estadio más avanzado) y que el momento actual depara apenas una unión aduanera sui generis (inmersa en una serie de vicisitudes como las ostensibles asimetrias de los paises componentes y una inusitada crisis entre los gobiernos uruguayo y argentino por los peligros de contaminación ambiental que podría generar el funcionamiento de plantas de producción de celulosa sobre la margen del rio Uruguay), se impone el interrogante planteado desde el epigrafe para intentar dilucidar si los socios iniciales del esquema integrativo se encuentran normativa y/o jurisprudencialmente preparados para afrontar la implementación de una estructura supranacional ${ }^{11}$ receptora de competencias o potestades atribuido-cedidas ${ }^{12}$, delegadas o transferidas (de acuerdo con la opción lingüistico-sustancial que se escoja) por aquellos. Como puede suponerse, tal paso tendría varias implicancias, entre ellas, una fuerte repercusión sobre el entramado federal en los Estados que escogieton semejante modalidad de organización político-territorial para articularse.

De cualquier modo, y si convergiera realmente la voluntad politica de avanzar hacia modalidades más intensas de relacionamiento integrativo, los paises componentes del modelo deberian encarar una compatibilización constitucional que acuerde aplicación preferente a los instrumentos internacionales en general (incluidos los de integración regional) sobre el derecho interno, complementada con una "cláusula de habilitación" para tomar parte de estructuras supranacionales. Se corporiza aqui una asimetria gravitante: la juridica, trasuntada en las diferencias normativo-constitucionales que se hacen perceptibles en el particular.

No es un dato precisamente insignificante que por conducto de uno de los objetivos centrales del Mercosur, fijado ya en el propio Tratado de Asunción, se instaló el compromiso entre los Estados Partes de armonizar sus legislaciones para lograr el fortalecimiento del proceso de integración. Tal premisa, según interpretamos, no queda exclusivamente anclada en la exigencia de coordinación de preceptos infraconstitucionales, sino que se traslada además al requerimiento de acondicionar las Constituciones en caso de que exista real intención política de moverse hacia niveles integrativos más intensos y demandantes como serian un mercado común o una unión económica.

II En torno al tema, sid. BAZAN, Victor, por ejemplo en "Hacia la pervivencia del Mercosur: nivelación constitucional, establecimiento de instituciones supranacionales y efectiva protección de los derechos humanos", en Binart Campos, Germán J. y Gil. Dominouez. Andrés (coordinadores), El Derecho Constitucional del siglo XXI. Diagnóstico y perspectivas, Buenos Aires: Ediar, 2000, pp. 275/309.

12 Puede consultarse con provecho, y con alcance que excede el caso español, el análisis que formula LoPEz CAsTilio respecto de lo que denomina el tándem conceptual de atribución-cesión de competencias derivadas de la Constitución que, a su criterio, emplea el art. 93 de la Ley Fundamental española (Lopez Castilto, Antonio, Constitución e integración, Madrid: Centro di Estudios Constirucionales, 1996, pp. 67 y ss.). 


\section{Repaso iuscomparativo}

\section{A) Argentina y Paraguay}

Telegráficamente adelantamos que en los casos de Argentina y Paraguay, sus respectivas Constituciones contienen disposiciones especificas para definir la valencia jerárquica de los instrumentos internacionales frente al derecho interno y, aunque con diferencias entre ambas regulaciones, se trazan las lineas que enmarcan las normas de habilitación en el sentido adelantado.

\section{a) Argentina}

En cuanto al rango de los documentos internacionales en la órbita normativa interna ${ }^{13}$, se ha dado un importante paso, pues la reforma constitucional de 1994 ha adjudicado a los instrumentos internacionales (incluidos los de integración y las normas que se dicten en su consecuencia) una jerarquia superior a la de las leyes nacionales -art. 75 , incs. 22 , párr. $1^{\circ}$, y 24-, al tiempo de haber acordado jerarquia constitucional a once instrumentos internacionales sobre derechos humanos (enumerados en el art. 75 , inc. $22,2^{\circ}$ párr.) y a los que en el futuro se les acuerde tal valencia (párr. $3^{\circ}$ de dicho inciso) $)^{14}$.

Por tanto, podria decirse coloquialmente que existen instrumentos internacionales relativos a derechos humanos que ostentan jerarquia constitucional originaria y otros que receptan jerarguia constitucional derivada.

Entre los primeros, es decir, los enumerados especificamente por la Ley Fundamental, se encuentran: la Declaración Americana de los Derechos y Deberes del Hombre; la Declaración Universal de Derechos Humanos; la Convención Americana sobre Derechos Humanos; el Pacto Internacional de Derechos Económicos, Sociales y Culturales; el Pacto Internacional de

15. Sobre este punto, entre otros trabajos de BazAiv, Victor, ver sobre la cuestión en el derecho comparado, "Conexiones y tensiones entre el derecho internacional de los derechos humanos y el derecho interno en Latinoamérica", en Velasquez Ramirez, Ricardo y Bobadilla Reyes, Humberto (coordinadores), Justicia constitucional, derecho supranacional e integración en el derecho latinoamericano, Memoria de la VII Convención Latinoamericana de Derecho (Santiago de Chile, 8 a 12 de octubre de 2007), Lima: Grijley, 2007, pp. $269 / 307$.

14 La atribución de jerarquia constitucional se hizo en las condiciones de vigencia de los instrumentos internacionales citados en el aludido párr. $2^{\circ}$ del inciso analizado, además de consignar que aquellos no derogan articulo alguno de la primera parte de la Constitución (es decir, la parte dogmática) y que deben entenderse complementarios de los derechos y garantias por ella reconocidos. Asimismo, en el párr. $3^{\circ}$ de ese inciso se ha estaruido el procedimiento para adjudicar tal valencia, luego de su aprobación por el Congreso, a otros tratados y convenciones sobre derechos humanos más alla de los que la Ley Fundamental nomina primigeniamente. 
Derechos Civiles y Politicos y su Protocolo Facultativo; la Convención sobre la Prevención y la Sanción del Delito de Genocidio; la Convención Internacional sobre la Eliminación de todas las Formas de Discriminación Racial; la Convención sobre la Eliminación de todas las Formas de Discriminación contra la Mujer; la Convención contra la Tortura y otros Tratos o Penas Crueles, Inhumanos o Degradantes; y la Convención sobre los Derechos del Niño.

Ya en la segunda modalidad procedimental, esto es, los ungidos con valencia constitucional ex post, se cuentan la Convención Interamericana sobre Desaparición Forzada de Personas, consagrada por la 24a Asamblea General de la OEA, celebrada el 9 de junio de 1994 en Belem do Pará, Brasil, y a la que se le dispensó tal cotización constitucional por conducto de la Ley 24.820, publicada el 29 de mayo de 1997; y la Convención sobre la Imprescriptibilidad de los Crimenes de Guerra y de los Crímenes de Lesa Humanidad, a la que se ha conferido esa valia mediante la Ley 25.778, publicada el 3 de septiembre de 2003.

A su tiempo, por imperio del aludido artículo constitucional 75 , inc. 24 , párr. $1^{\circ}$, se faculta al Congreso a aprobar tratados de integración que "deleguen" competencias ${ }^{15}$ y jurisdicción a organizaciones supraestatales en condiciones de reciprocidad e igualdad, y que respeten el orden democrático y los derechos humanos, advirtiendo que las normas dictadas en su consecuencia tienen jerarquia superior a las leyes.

En consecuencia, el precepto mencionado en último término ha brindado habilitación constitucional, por ejemplo, para la creación de tribunales supranacionales receptores de la jurisdicción delegada, terminologia que, más allả de alojar alguna imprecisión, ha sido la escogida por la Norma Básica.

Además, la disposición nombrada (en su párr. $2^{\circ}$ ) ha efectuado una distinción en cuanto al procedimiento y a las mayorias parlamentarias requeridas para la aprobación de dichos tratados. si éstos son suscriptos con Estados latinoamericanos o con otros que no lo sean: en el primero de los casos, se requiere la mayoría absoluta de la totalidad de los miembros de cada Cámara;

15 Es importante destacar que ya el "Dictamen preliminar del Consejo para la Consolidación de la Democracia" estimaba conveniente "establecer entre las facultades asignadas al Congreso de la Nación la de delegar ciertas competencias a entes supranacionales, conforme lo establezca la Constitución", advirtiendo que "si tal facultad no se estableciera en la misma Carta Magna, el tratado en virtud del cual se delegasen competencias a un ente supranacional, en principio, no gozaria de legalidad porque iria en contra de la misma Constitución ya que ninguin tratado, según el articulo 27 , podria contrariar los principios constitucionales". Además, planteaba la modificación del entonces art. 94 (actual art. 108), en orden a habilitar instancias jurisdiccionales internacionales superiores a la Corte Suprema de Justicia de la Nación, con el objeto de adecuar nuestro ordenamiento juridico positivo a los rratados internacionales y, particularmente, al Pacto de San José de Costa Rica (Reforma constitucional: Dictamen preliminar del Consejo para la Consolidación de la Democracia, Buenos Aires: Eudeba, 1986, pp. 82/83). 
mientras que en el último, con la mayoría absoluta de los miembros presentes de cada Cámara, y como primer paso, se declarará la conveniencia de la aprobación del tratado y, como segunda fase, será aprobado el mismo solo con el voto de la mayoría absoluta de la totalidad de miembros de cada Cámara, después de ciento veinte días del acto declarativo.

Asimismo, en el parr. final del art. 75 , inc. 24 , se establece que la denuncia de los tratados a que se refiere el inciso, exigirá la previa aprobación de la mayoria absoluta de la totalidad de los miembros de cada Cámara.

Por lo demás, la jurisprudencia de la Corte Suprema de Justicia viene acompañando sostenidamente, al menos desde 1992 (in re "Ekmekdjian, Miguel Á. c/ Sofovich, Gerardo y otros" ${ }^{16}$ ), el sitio preferente que los instrumentos internacionales ostentan de cara al derecho vernácu$10^{17}$.

\section{b) Paraguay}

Una respuesta constitucional equivalente a la argentina, podría extraerse de una interpretación dinámica del art. 145 de la Constitución paraguaya (de 1992) y de los arts. 137 y 141 , ibid.; cuadro normativo del que es dable predicar, por un lado, la convergencia de una regla de habilitación y, por el otro, la primacia de los tratados, convenios y acuerdos internacionales aprobados y ratificados, sobre las leyes dictadas por el Congreso.

Aquel art. 145 prevé que la República del Paraguay admite -en condiciones de igualdad con otros Estados- un orden juridico supranacional que garantice la vigencia de los derechos humanos, la paz, la justicia, la cooperación y el desarrollo, en lo politico, económico, social y cultural. La cláusula advierte que dichas decisiones (relativas a la norma de habilitación -según nuestra lectura del tema-) sólo podrán adoptarse por mayoria absoluta de cada Cámara del Congreso.

Dato especialmente relevante es, por ende, la decisión de dar vida a una norma específica sobre el "orden juridico supranacional", separada de las disposiciones relativas a los tratados internacionales en general, de lo que se deduce la concepción autónoma que sobre aquella temática impregnó la mirada del constituyente.

10. Fallos, 315:1492 (7 de julio de 1992).

Algún pronunciamiento anterior a "Ekmekdjian c/ Sofovich" sobre la interpretación de la normativa de un instrumento internacional se patentiza embrionariamente en el caso "Firmenich, Mario E." (Fallos, 310:1476, de 28 de julio de 1987), acerca de la hermenéurica "razonable" del art. 7.5 de la Convención Americana sobre Derechos Humanos (ver considerandos $4^{\circ}, 6^{\circ}$ y $7^{\circ}$ de la mayoria).

It Sobre el tema, vid. BAzAN, Victor, "El derecho internacional de los derechos humanos y el derecho interno en el escenario argentino: convergencias y desencuentros", El Derecho, Buenos Aires, 16 de noviembre de 2007, pp. $1 / 10$. 
Por su parte, el art. 137, párr. $1^{\circ}$, establece un orden prelativo de disposiciones que considera integrantes del derecho positivo nacional, en el que -luego de entronizar en su cúspide a la Constitución Nacional- enuncia a los tratados, convenios y acuerdos internacionales con anterioridad a las leyes dictadas por el Congreso, de donde los mencionados instrumentos internacionales -debidamente aprobados y ratificados- tendrian una jerarquia supralegal mas infraconstitucional, apuntalada por el propio art. 141, ibid., que preceptúa que "[l]os tratados internacionales válidamente celebrados, aprobados por ley del Congreso, y cuyos instrumentos de ratificación fueran canjeados o depositados, forman parte del ordenamiento legal interno con la jerarquía que determina el artículo 137 " (remarcado añadido).

Otro aspecto no desdeñable en la linea anunciada es el preámbulo, segmento constitucional que -como se sabe- ilumina axiológicamente la labor de interpretación de la Ley Fundamental, encargándose de advertir que el pueblo paraguayo sanciona y promulga la Constitución "reconociendo la dignidad humana con el fin de asegurar la libertad, la igualdad y la justicia, reafirmando los principios de la democracia republicana, representativa, participativa y pluralista, ratificando la soberania e independencia nacionales, e integrado a la comunidad intemacional" (énfasis agregado).

Para concluir, y si bien queda en claro la cotización subconstitucional de los instrumentos internacionales, debe igualmente destacarse que la jurisprudencia de la Corte Suprema de Justicia de la Nación, Sala Constitucional, se ha decantado por interpretar y declarar expresamente el valor supralegal de dichos documentos internacionales; por ejemplo, en Acuerdo y Sentencia No 59/2001, de 20 de marzo, y ํo 126/2002, de 19 de marzo.

B) Brasil y Uruguay

El paisaje cambia de fisonomía en los casos brasileño y uruguayo, no solo por algunas carencias normativo-constitucionales (al no contar con reglas que claramente fijen la ubicación de los instrumentos internacionales en relación con los respectivos ordenamientos juridicos internos), sino también en función de ciertos criterios jurisprudenciales alli predominantes.

Justamente, una cuestión indiscutible radica en que el vacio normativo en torno a la interrelación de los instrumentos internacionales y el derecho interno, hace que la labor jurisprudencial que al respecto tracen los respectivos órganos de cierre de la jurisdicción constitucional adquiera un claro valor añadido, desde que les corresponde marcar los ejes interpretativos idóneos para desentrañar la posición asignable a los señalados instrumentos y normas consuetudinarias internacionales vis-äwis el derecho doméstico.

a) Brasil

Aun cuando el art. 4, parágrafo único, de la Ley Fundamental de 1988 establezca que "Illa República Federativa del Brasil buscará la integración económica, política, social y cultural de 
los pueblos de América Latina, con vistas a la formación de una comunidad latinoamericana de naciones"; no parece más que una declaración programática. Sobre todo, porque en la jurisprudencia del Supremo Tribunal Federal (y a salvo ciertas excepciones -por ejemplo, en punto al art. 98 del Código Tributario Nacional y en materia de extradición-) el criterio que prevalece en torno a la relación entre ley federal y tratado internacional es el de paridad jerárquica, es decir, que en cualquier caso este ưltrimo tendrá siempre cotización infraconstitucional y en ocasiones podrá ser inaplicado al quedar desplazado por la preferente valia de la ley interna, ya que en supuesto de conflicto que resulta operativa la pauta de sucesión normativa, o sea, que la norma posterior deroga a la anterior, o la de especialidad, en cuanto a que la norma especial se impone sobre la general.

Asi, en alguna oportunidad resolvió que "los actos internacionales, una vez regularmente incorporados al derecho interno, se situen en el mismo plano de validez y eficacia de las normas infraconstitucionales (... consagrändose) la tesis (...) de que existe, entre tratados internacionales y leyes internas brasileñas, de carácter ordinario, mera relación de paridad normativa" ${ }^{18}$ (bastardilla nuestra).

En realidad, tal solución reconoce como génesis el acople de dos precedentes: uno, de 1971, ventilado en el "Recurso Extraordinario $N^{\circ} 71.154$ " -rel. min. Osvaldo Triguero-, en el que -según Fontoura ${ }^{19}$ - el razonamiento del Supremo Tribunal radicó en analizar la Constitución en forma colectiva y, por tal via y utilizando un juicio analógico, se colocaba al tratado a la misma altura de la ley ordinaria, esto es, categorizando a ambos instrumentos como leyes de idéntica naturaleza; otro, de 1977, al resolver el "Recurso Extraordinario No 80.004" -rel. min. Javier de Albuquerque-, que concluyó que la ley ordinaria posterior al tratado podia modificar a este. Agrega Fontoura que, en este último fallo, se utilizó una forma elegante para aplicar un criterio dualista usando el razonamiento de la teoria monista, ya que si bien no se negaba la existencia del tratado, se argumentaba que, por la fuente diversa, internamente prevaleceria el ordenamiento juridico nacional, sin perjuicio de la responsabilidad estatal en el campo inter. nacional ${ }^{20}$.

is Cfr. Supremo Tribunal Federal de Brasil, in re Carta Rogatoria N0 8.279.4. Republica Argentina, sentencia de 4 de mayo de 1998. El párrafo trascrito trasuntaba el criterio del Supremo Tribunal Federal respecto de la solicitud de exequatur de una rogatoria sustentada en el Protocolo de Medidas Cautelares aprobado por el Consejo Mercado Común del Mercosur. Con posterioridad a tal fallo, el mencionado Protocolo fue incorporado al ordenamiento juridico del vecino pais, por medio del Decrero $\mathrm{N}^{\circ} 2.626$, de 15 de junio de 1998 .

En sentido análogo a la resolución impresa a la citada Carta Rogatoria $\mathrm{N}^{\circ} 8.279 .4$, y además de los dos precedentes a los que haremos referencia en el texto (RE N 71.154 y $R E N^{\circ} 80.004$ ), ver: ADI No 1.480-DE, rel. min. Celso de Mello; RTJ 70/333; RTJ 100/1030; RT 554/434 (cttar. La Ley, Buenos Aires, 11 de agosto de 1998, pp. 4/6).

19. Fontoukd, Jorge, "Solución de controversias en el derecho comunitario. Los impasses en la construcción de un sistema", Sobución de controtersias, publicación del Seminario "Solución de controversias y medios institucionales para la resolución de los conflictos de intereses" (Buenos Aires, 15 y 16 de noviembre de 1995), edit. por Mi. nisterio de Relaciones Exteriores, Comercio Internacional y Culto, Buenos Aires, 1996, p. 28.

20. İem. 
Debe no obstante advertirse que se observa cierto progreso en el panorama brasileño en relación con los instrumentos internacionales sobre derechos humanos, fundamentalmente a partir de la Enmienda Constitucional $\mathrm{N}^{\circ} 45$ de 2004, que incluyó el $\$ 3^{\circ}$ al art. 5 de la Constitución Federal, disponiendo que "[1] os tratados y convenciones internacionales sobre derechos humanos que fueran aprobados, en cada Cámara del Congreso Nacional, en dos turnos, por tres quintos de los votos de los respectivos miembros, serán equivalentes a las enmiendas constitucionales" (remarcado agregado). Por su parte, está gestándose por estos días (finales de 2007) lo que quizá plasme en una importante modificación jurisprudencial del Supremo Tribunal Federal al concederles ya oficialmente valencia supralegal aunque infraconstitucional a los documentos sobre aquella materia, lo que sucederia en el "Recurso Extraordinario $\mathrm{N}^{\circ}$ 466.343-1", São Paulo, rel. min. Cezar Peluso, Recurrente: Banco Bradesco S.A., Recurrido: Luciano Cardoso Santos, actualmente en trámite ante dicho Supremo Tribunal, donde está en discusión un importante voto proferido por el min. Gilmar Mendes que postula la posición anticipada.

Pese a tal avance, persisten algunos obstáculos pues por ejemplo tenemos entendido que se mantiene (aunque ahora en cabeza del Superior Tribunal de Justicia) la exigencia de homologación de sentencias extranjeras y la concesión de exequatur a las cartas rogatorias (art. 105.I. 'i'), sumado a que Brasil aún no ratifica la Convención de Viena sobre el Derecho de los Tratados.

b) Uruguay

El contexto constitucional uruguayo tambièn se caracteriza por la ausencia de normas sobre el emplazamiento jerárquico de los instrumentos internacionales frente al derecho interno. Tampoco cuenta con una cláusula de habilitaciỏn que permita atribuir facultades o competencias a organismos supranacionales. A nuestro juicio, en el enlace de ambos elementos radica el núcleo del problema, por supuesto, desde el plano jurídico.

Por lo demás, si bien existe consenso doctrinario en el sentido de que el Tratado de Asunción no ofreceria una incompatibilidad con la Carta Magna de ese pais (que entrara en vigor en 1967), sobre todo en una etapa predominantemente caracterizada por la intergubernamenta* lidad, no existe acuerdo absoluto acerca de si una profundización del ligamen signada por la transferencia (cesión, atribución, delegación, traspaso, etc.) de competencias hacia organismos supranacionales habilitados para emitir normas de aplicación directa, inmediata y preferente sobre el derecho interno, resultaria inconstitucional, en particular visàvis la previsión del art. 4 de la Ley Fundamental, que dispone: "La soberania en toda su plenitud existe radicalmente en la Nación, a la que compete el derecho exclusivo de establecer sus leyes".

La postura que responde afirmativamente al interrogante, a la que adherimos, es sustentada -entre otros autores- por Gros EsfiLL, quien entiende que "desde el momento en que los 
órganos se integran con individuos independientes de la voluntad de los Estados signatarios, como es el caso de los tratados de integración europea (...) la cuestión se hace más dificultosa, obligando a encarar, en el caso de Uruguay, una reforma constitucional para poder llegar a admitir esa posibilidad"21 (énfasis agregado).

Quizá se dejó escapar una buena oportunidad en ocasión de la reforma constitucional plebiscitada el 8 de diciembre de $1996^{22}$, y alguna ulterior ${ }^{23}$, para introducir una cláusula de habilitación en la Constitución Nacional, al estilo de la previsión argentina, que despejara dudas, no dejara sujeta a labilidades interpretativas una cuestión de suma trascendencia como la que abordamos y que exhibiera la verdadera decisión política de generar una disposición constitucional que permita sin ambages a Uruguay integrar estructuras supranacionales.

Al respecto, en linea con lo anticipado, concidimos con Risso FERRAND cuando afirma que la cuestión de la jerarquia de los tratados internacionales en el ordenamiento interno uruguayo debe ser objeto, reforma constitucional mediante, de una solución clara, superando la actual incertidumbre jurídica, nunca deseada ni admisible en un proceso de integración; para lo cual propone que la Constitución habilite el pasaje a instancias superiores de integración (con traspaso o delegación de atribuciones a entes supranacionales), previendo no solo esta modalidad sino también la existencia del derecho comunitario derivado, con disposiciones expresas y claras acerca de su jerarquia jurídica respecto a las normas propias del derecho interno ${ }^{24}$.

Para concluir, cabe advertir que en algún momento la Suprema Corte de Justicia, interpretó, con alegado apoyo en Justino Jtménez de AréChaga y SupERVIEl le, que " ... cabe compartir la tesis que la ley ulterior al tratado, inconciliable con éste, supone su derogación..." (remarcado nuestro). Este criterio fue expuesto por el Máximo Tribunal uruguayo in re "G.S., J. con A. del U. y C.U. S.A., Reinstalación, Casación”, Ficha 357/989, Montevideo, de 20 de junio de $1990^{25}$.

21 Gros Espielt, Héctor, "El Tratado de Asunción: Una aproximación a su problemática juridica", Revista de la Facultad de Derecho, № 1, Montevideo: Universidad de la República, 1991, p. 16, citado por LivDon! Sosa, Ảngel, "La solución de conflictos en el Mercosur", Revista del Colegio de Abogados de La Plata, Año XXXIV, N" 54, Buenos Aires, marzojunio 1994, p. 332.

21 Diario Oficial de 9 de enero de 1997.

23. Hasta donde alcanza nuestra información, ulterior modificación constitucional a la plebiscitada el 8 de diciembre de 1996, fue la sometida a idéntico procedimiento plebiscitario el 31 de octubre de 2004.

24. Risso Ferrand, Martin, Derecho Constitucional, Tº 1, 2 ed. actualiz, y ampl, Montevideo: Fundación de Cultura Universitaria, 2006, pp. $383 / 384$.

25. El texto de la sentencia puede compulsarse en Revista Unuguaya de Derecho Constitucional y Politico, $\mathrm{T}^{\circ} \mathrm{VII}, \mathrm{N}^{\circ} 37$, junio-julio 1990, Montevideo, pp. 32/39. El pärrafo trascrito luce en p. 38. 


\section{C) Venezuela}

Con visión prospectiva y aguardando el desarrollo de los acontecimientos, incluimos en este punto a Venezuela, que -como vimos (nota 6 a pie de página)- ha exteriorizado su voluntad de incorporarse plenamente al Mercosur.

De un veloz recorrido por la normativa constitucional del país caribeño (de 1999) puede concluirse que, al menos desde el plano normológico, presenta varios aspectos positivos de cara al involucramiento en procesos integrativos, aunque quizá en el "debe" pueda contabilizarse que, al igual que Brasil, no ha ratificado la Convención de Viena sobre el Derecho de los Tratados, además de que muestra alguna jurisprudencia preocupante de la Sala Constitucional del Tribunal Supremo de Justicia (TSJ) que, aunque vinculada al tema de los derechos humanos, deja al descubierto ciertas aristas conflictivas que exceden tal tópico.

A continuación desgranaremos los aspectos positivos, dejando para el final una brevisima alusión sobre el citado antecedente jurisprudencial que generó polémica doctrinal.

a) En primer lugar, cuenta con un sistema de control de constitucionalidad previo de los instrumentos internacionales. En efecto, es de competencia de la Sala Constitucional del TSJ, verificar a solicitud del Presidente o Presidenta de la República o de la Asamblea Nacional, la conformidad con la Constitución de los tratados internacionales suscritos por la República antes de su ratificación (ordinal $\left.5^{\circ}\right)^{26}$. Siendo así, cuando menos en la dimensión teórica, si la Sala Constitucional no encuentra óbice de tal calibre al documento internacional en cuestión, éste no podria (al menos no deberia) ser atacado en el futuro por medio de una fiscalización represiva o posterior ni tampoco plantearse luego una acción de inconstitucionalidad contra la ley que lo aprueba.

Juzgamos que tal solución (contralor constitucional previo de los instrumentos internacionales) es fundamental en procesos de integración supranacional, pues en la práctica (y como afirma BREWER-CARLAS) llevaria a la ratificación de los tratados respectivos solo después de la verificación de su constitucionalidad por el Tribunal Supremo y evitar, asi, la impugnación posterior de la ley aprobatoria de los tratados, como ocurriera en los casos de los tratados relativos al Acuerdo de Integración de la ahora Comunidad Andina, lo que sucedió -vale aclarar por nuestra parte-con anterioridad a la entrada en vigencia de la actual Constitución ${ }^{27}$.

26. Texto constitucional "corregido" y que varía del aptobado en el referéndum de 15 de diciembre de 2000 y publicado el 30 de diciembre de 1999, que establecia la "conformidad de la Constitución con los tratados internacionales" -énfasis propio- (cfr. BREWER-CaRiAs, Allan R., "La Justicia Constitucional en la Constitución venezolana de 1999", en Ferrer MaC-Gregor, Eduardo [coordinador], Derecho Procesal Constitucional, 2" ed., México, D.F.: Colegio de Secretarios de la Suprema Corte de Justicia de la Nación, Porrúa, 2001, p. 948 ).

27. Idem. 
b) En segundo lugar, cuenta con una "norma de habilitación", el art. 153, el que luego de advertir que la República promoverá y favorecerá la integración latinoamericana y caribeña, en aras de avanzar hacia la creación de una comunidad de naciones, defendiendo los intereses económicos, sociales, culturales, politicos y ambientales de la región, que podrá suscribir tratados internacionales que conjuguen y coordinen esfuerzos para promover el desarrollo común de sus naciones, y que aseguren el bienestar de los pueblos y la seguridad colectiva de sus habitantes; agrega que, para tales fines, "podrá atribuir a organizaciones supranacionales, mediante tratados, el ejercicio de las competencias necesarias para llevar a cabo estos procesos de integración" (remarcado agregado).

c) Por último, el segmento final de la norma citada en el subapartado anterior es muy importante, ya que después de señalar que las normas que se adopten en el espectro de los acuerdos de integración serán consideradas parte integrante del ordenamiento legal vigente, consagra los caracteres básicos del derecho comunitario, al mencionar que tales normas serản "de aplicación directa y preferente a la legislación intema" (énfasis agregado).

En linea con ello se ubica otra regla relevante localizada en el art. 318 , párr. $1^{\circ}$, donde si bien se prevé que la unidad monetaria de la República Bolivariana de Venezuela es el bolivar, dispone que "[e]n caso de que se instituya una moneda común en el marco de la integración latinoamericana y caribeña, podrá adoptarse la moneda que sea objeto de un tratado que suscriba la República".

d) El polémico decisorio de la Sala Constitucional al que nos referiamos es la Sentencia 1.942 , de 15 de julio de 2003 , que reitera la doctrina de su predecesora $1.013^{28}$ y que no fue precisamente bien recibida por la doctrina especializada ${ }^{29}$.

Tal pronunciamiento convalidó el delito de desacato, al conocer de una acción de nulidad por inconstitucionalidad contra varios articulos del Código Penal que establecen esa figura o permiten la utilización de otras normas de la legislación penal de la misma manera y con idénticos fines. Al efecto, y luego de recordar la previsión del articulo 23 constitucional en cuanto a que las disposiciones de los tratados, pactos y convenciones relativos a derechos humanos adquieren rango constitucional, estando equiparadas a normas contenidas en la Constitución, puntualizó que aquella cláusula establece una prevalencia de normas, pero no de fallos o dictámenes de instituciones, resoluciones de organismos, etc. En otras palabras, pero siempre siguiendo la posi-

28 Dictada en fecha 12 de junio de 2001.

29 Ver, por ejemplo, Ayala COkAO, Carlos, "La sentencia $1.942 \mathrm{vs}$, la protección internacional de la libertad de expresión", en Derecho Constitucional e institucionalidad democrática, $\mathrm{T}^{\circ} \mathrm{I}$, ponencias del "VIII Congreso Venezolano de Derecho Constitucional' desarrollado en Valencia (Venezuela), 26 a 28 de noviembre de 2003, Asociación Venezolana de Derecho Constitucional, pp. 433/505. 
ción delineada por la Sala, la nombrada prevalencia no alcanza a los informes u opiniones de organismos internacionales que pretendan interpretar el alcance de las normas de los instrumentos internacionales, pues el único capaz de interpretarlas, con miras al derecho venezolano, es el juez constitucional, conforme al articulo 335 de la vigente Constitución, en especial, al intérprete nato de la Constitución de 1999, y, que es la Sala Constitucional.

En consecuencia, esta última moldeó un criterio discutible en cuanto a la interacción del derecho internacional de los derechos humanos y el derecho interno, vehiculo una involución interpretativa en la materia al blandir un concepto de soberania hace tiempo superado y dejó de acatar las obligaciones emergentes de los tratados internacionales relativos a dicho campo temático al considerar que las recomendaciones contenidas en los informes adoptados por la Comisión Interamericana "no son obligatorias" y que las sentencias de la Corte Interamericana, "para ser ejecutadas dentro del Estado, tendrán que adaptarse a su Constitución", con lo cual, adjudica al juez nacional facultades de control y escrutinio de los pronunciamientos de dichos órganos protectorios interamericanos ${ }^{30}$.

Además de poner en entredicho lo dispuesto por el articulo 23 constitucional, la resolución dejó en un cono de sombras a la previsión del art. 31 , ibid., que en su párr. $1^{\circ}$ determina que "toda persona tiene derecho, en los términos establecidos por los tratados, pactos y convenciones sobre derechos humanos ratificados por la República, a dirigir peticiones o quejas ante los órganos internacionales creados para tales fines, con el objeto de solicitar el amparo a sus derechos humanos", agregando en su $2^{\circ}$ párr. que el Estado adoptará -conforme a procedimientos establecidos en la Constitución y la ley-, "las medidas que sean necesarias para dar cumplimiento a las decisiones emanadas de los órganos internacionales previstos en este artículo" (en ambos casos los remarcados nos corresponden).

Finalmente, es de destacar que la cuestión generada por la Sentencia $\mathrm{N}^{\circ} 1.942$ fue planteada ante la Comisión Interamericana de Derechos Humanos, la que, a su vez, solicitó medidas provisionales a la Corte Interamericana de Derechos Humanos. Estas fueron concedidas por el Tribunal, pero ante el incumplimiento del Estado venezolano y la denuncia realizada en tal sentido por la Comisión Interamericana, aquel emitió una resolución conjunta en fecha 4 de mayo de 2004, relativa a las medidas provisionales respecto de Venezuela en cuatro casos, entre los que se cuenta el que aqui nos ocupa. Entre otros puntos, declaró: a) que por haber reconocido su competencia, Venezuela está obligada a cumplir las decisiones de la Corte Interamericana de Derechos Humanos, la que tiene el poder, inherente a sus atribuciones, de supervisar el cum-

30 Debe tenerse presente que Venezuela es Estado Parte de la Convención Americana de Derechos Humanos desde el 9 de agosto de 1977 y, de acuerdo con el art. 62 de esta, reconoció la competencia contenciosa de la Corte Interamericana el 24 de junio de 1981 . 
plimiento de las mismas; y b) que dicho Estado tiene la obligación de implementar las medidas provisionales ordenadas por la Corte y de presentar, con la periodicidad que ésta indique, los informes requeridos y, además, que la facultad de la Corte incluye evaluar los informes presentados, y emitir instrucciones y resoluciones sobre el cumplimiento de sus decisiones.

D) Balance

a) El trayecto analitico que nos condujo por algunos de los pliegues del derecho y la jurisprudencia comparados de los paises que integran el Mercosur ( $y$ de Venezuela, que aspira a incorporarse plenamente a él), pone al descubierto una heterogeneidad de soluciones que cons. pira contra la posibilidad de cumplir los ambiciosos propósitos declamados -particularmente, el advenimiento de un mercado común u otra estructura integrativa superior-, por lo que si confluye una real voluntad politica no dejaria de ser aconsejable intentar una nivelación constitucional y jurisprudencial, que brinde el sustento necesario para que germine saludablemente el modelo integrativo seleccionado.

b) No deberia perderse de vista que el derecho comunitario tiene como caracteres predominantes su autonomia, el efecto directo y la aplicación inmediata y preferente de sus normas, caracteristicas que -en conjunto- convergen hacia la prevalencia del orden juridico comunitario en relación con las normativas internas de los Estados que conforman el espacio regional de que se trate.

Lo dicho amerita un par de consideraciones explicativas, que delinearemos a continuación, por cierto, sin visos de taxatividad,

En primer lugar, y como explica Alonso GaRCLA, la naturaleza autónoma del ordenamiento juridico comunitario se traduce en un sistema institucional propio, en cuyo marco se produce derecho y se controla el respeto de la constitucionalidad-legalidad comunitaria ${ }^{31}$. Tal naturaleza autónoma, añade el referido autor, incluye la participación de los ordenamientos juridicos nacionales: verticalmente, por medio de sus propias estructuras, complementarias del aparato institucional comunitario en su doble vertiente de producción juridica y de control jurisdiccional; y horizontalmente, aportando concepciones y técnicas nacionales en la configuración de las reglas de juego del sistema comunitario ${ }^{32}$.

Por su parte, uno de los caracteres salientes del derecho comunitario es el de la primacia, respecto del cual PUENTE EOIDO se encarga de aclarar que, bien interpretado, ese principio significa

31 Alonso Garcia, Ricardo, Derecho comunitario y derechos nacionales. Autonomia, integración e interacción, Buenos Aires: Abeledo-Perrot, 1999, p. 105.

31. Idem. 
que en caso de contradicción de una norma comunitaria con otra regla de un sistema juridico de un Estado Miembro (cualquiera sea su rango normativo) "el juez nacional ha de aplicar en el caso concreto la comunitaria e inaplicar la nacional" (remarcado del original), tratándose "de un estricto problema de aplicación preferente, porque al hacerlo asi, el juez nacional no induce en la regla inaplicada un principio de nulidad o anulabilidad. Esta sigue siendo plenamente válida y susceptible de ser aplicada en cualquier otro supuesto en el que no haya esa incompatibilidad", de lo que deduce el autor que la primacia nada tiene que ver con el principio de jerarquia normativa ${ }^{33}$.

c) Dentro de esas líneas contextuales, concretamente y para los casos de Brasil y Uruguay, aquella nivelación normativa podria venir de la mano de sendas reformas constitucionales, que atribuyan la legitimación suficiente para crear entes supranacionales receptores de competencias $\mathrm{O}$ atribuciones dispensadas por esos Estados.

De su lado, en los supuestos de Argentina y Paraguay, y con sus peculiaridades, puede concluirse que sus sistemas constitucionales se encuentran suficientemente acondicionados para emprender semejante intensificación del ligamen integrativo.

Finalmente, y siempre desde la vertiente normativa, el contexto jurídico venezolano también estaria adaptado para avanzar hacia estructuras integrativas más complejas, incluso con un interesante plus de tutela preventiva al estar institucionalizado en la Ley Fundamental un modelo de control de constitucionalidad previo de los tratados internacionales, lo que impediria (al menos desde una óptica especulativa o teórica) "sorpresas" ulteriores cuando el instrumento en cuestión ya esté vigente, sorteando el riesgo de que el Estado incurra en responsabilidad internacional. Sin embargo, y para evitar una lectura parcializada del enfoque, cabe llamar la atención sobre el discutible criterio que la Sala Constitucional del TSJ sentara en la reseñada Sentencia $\mathrm{N}^{\circ} 1.942$, brindando una devaluada cotización a los pronunciamientos de los órganos protectorios interamericanos en materia de derechos humanos (Comisión y Corte Interamericanas) al entenderlos sometidos al control y escrutinio posteriores por parte del juez nacional a los fines de su eventual cumplimiento.

IV. CIERTAS CUESTIONES CONFLICTIVAS QUE SURGEN DE LA INTERRELACIÓN DE LA INTEGRACIÓN SUPRANACIONAL Y EL FEDERALISMO Y DE LA BÚS. QUEDA DE INSTANCIAS DE PARTICIPACIÓN DE LOS ENTES SUBESTATALES

\section{Perfiles de la cuestión}

35 Puente Egido, José, "El impacto del derecho comunitario europeo en la Constitución Española", en DrNAS DE Ciement, Zlata (coordinadora), Estudios de Derecho Intemacional. En homenaje al Profesor Emesto J. Rey Caro, T II, Cordoba: Drnas - Lerner edirores, 2002, p. 1654. 
Básicamente, el propósito de este segmento del trabajo es enfocar algunos aspectos de interés relativos, por ejemplo, a la posibilidad de que las entidades infranacionales desplieguen cierto tipo de actividad en el ámbito internacional o de que se generen a su respecto alternativas de participación en el proceso integrativo en los planos interno o externo.

En definitiva, se trata de amortiguar con recursos descentralizantes el impacto que sobre tales esferas infraestatales puede provocar el fenómeno integrativo, que genera vectores centri. petos cobijados en el ente comunitario.

En cada pais de estructura compleja deberán buscarse espacios en el espectro interno o en el internacional para habilitar vías de actuación en el proceso de integración por parte de los Estados, el Distrito Federal y los Municipios, en el caso del Brasil; las provincias, las regiones (aunque no sean instancias politicas), los municipios y la Ciudad Autónoma de Buenos Aires (CABA), en el supuesto de Argentina; y los Estados, el Distrito Capital, las dependencias federales y los territorios federales, en el ámbito de Venezuela.

Más allá de todo ello, se mantienen vivas naturalmente las posibilidades que per se tales entidades subestatales puedan buscar ad extra o las que el propio contexto normativo comunitario pudiera depararles. Por supuesto, siempre dejando a buen resguardo los limites establecidos por las respectivas configuraciones constitucionales y los repartos competenciales que éstas diseñen.

\section{El caso argentino}

A modo de caso testigo, plantearemos ciertos puntos temáticos interesantes (algunos, con aristas conflictivas) que surgen de la Constitución argentina a partir de la reforma constitucional de 1994.

A) La regionalización

El artículo 124 constitucional acuerda a las provincias la facultad de crear regiones para el desarollo económico y social y establecer órganos con facultades para el cumplimiento de sus fines.

Tal premisa debe leerse en linea con el art. 125, parte inicial, ibid., que permite a las provincias la celebración de tratados parciales para fines de administración de justicia, de intereses económicos y trabajos de utilidad común, con conocimiento del Congreso; y con el art. 126, ibid., que paralelamente les proscribe ejercer el poder delegado a la Nación y la celebración de tratados parciales de carácter politico.

De tal trama normativa surge que la región no es una nueva instancia política en el sistema institucional argentino. Pero sin duda, es una importante herramienta de oxigenación federal, 
mas siempre como vehículo descentralizador, es decir, como advierte HERNÁNDEZ, no destinada a centralizar el pais o violar las autonomias provinciales y municipales ${ }^{34}$.

Aprovechamos este segmento del trabajo para reiterar nuestra posición en punto a que la creación de regiones en los términos del art. 124 de la Constitución Federal es una facultad provincial y no del gobierno nacional, lo que obviamente no significa que este deba desentenderse del proceso de regionalización, pues otra de las innovaciones vehiculadas por la reforma de 1994 y, en este caso, trasvasada al art. 75 , inc. 19 , párr. $2^{\circ}$, es la atribución conferida al Congreso en punto a proveer al crecimiento armónico de la Nación y promover politicas diferenciadas que tiendan a equilibrar el desigual desarrollo relativo de provincias y regiones, iniciativas para las cuales el Senado será Cámara de origen.

En otras palabras, las regiones no pueden ser pergeñadas por ley del Congreso y de espaldas a las provincias o en contra de la voluntad de estas, pues como agudamente ha advertido Gel.t, "In]o se trata de que el Estado Federal planifique una superestructura compuesta por regiones por sobre las provincias que implique, en los hechos, un corrimiento de los limites de estas. Por el contrario, la regionalización se constituye en un instrumento dé los entes locales para solucionar problemas comunes, maximizando las ventajas comparativas de cada una de las provincias que acuerdan crear una región, aunque sólo pueden hacerlo en materia económica y social" ${ }^{\prime 5}$.

Por lo demás, la politica de regionalización ad intra y ad extra (en el contexto integrativo del Mercosur) podrá coadyuvar, como ha sucedido en Europa y naturalmente teniendo en cuenta las significativas diferencias y evitando mimetismos juridicos artificiales, a la búsqueda de grados más avanzados de cohesión social y territorial y de desarrollo económico equilibrado.

En linea con ello, y para cerrar este punto, coincidimos con STÄHL respecto de las tres cuestiones centrales que plantea acerca de la existencia de una politica regional en el marco de un esquema de integración, las que tienen que ver con los objetivos generales perseguidos: la democratización del proceso integrador, la incorporación a este de una nueva dinámica y la corrección de los desequilibrios ${ }^{36}$.

34. Hersandez (h.), Antonio Maria, Integración y globalización: rol de las regiones, provincias y municipios, Buenos Aires; Depalma, 2000 , p. 41 .

35 GeLLL, Maria Angélica, Constitución de la Nación Argentina comentada y concordada, La Ley, $2^{2}$ ed. ampl. y actualiz., Buenos Aires, 2003, p. 861.

36 SтанHI. Jorge, "Participación de las regiones internas de los Estados en los procesos de integración", en un texto inédito que el autor (Profesor de Derecho Internacional Privado y de Derecho de la Integración de la Facultad de Derecho de la Universidad Nacional de Rosario), tuviera la gentileza de enviarnos. 
B) La actividad internacional de las provincias.

Nótese que el mencionado art. 124 de la Carta Fundamental prevé que las provincias "po. drán también celebrar convenios internacionales en tanto no sean incompatibles con la política exterior de la Nación y no afecten las facultades delegadas al Gobierno federal o al crédito público de la Nación; con conocimiento del Congreso Nacional".

La cuestión ha suscitado numerosas dudas en la doctrina tanto en torno al grado de legitimación de las provincias para actuar internacionalmente y al alcance de tal eventual actividad, como al calibre semántico de la expresión "con conocimiento del Congreso Nacional".

La problemática recepta importancia no sólo desde el plano especulativo o académico, sino fundamentalmente desde la óptica del refuerzo del federalismo, la tevalorización de las gestiones que en el ámbito internacional les es licito desplegar a las unidades provinciales y el rol que pueden jugar en el terreno de la integración supranacional, naturalmente dentro de los limites establecidos por la Ley Fundamental, lo que supone dejar a buen resguardo el principio juridico-axiológico de lealtad constitucional que, justo es decirlo, no solamente vincula a las entidades infraestatales respecto del gobierno central, sino que, en retroalimentación, también compromete a este con relación a aquellas.

Un enfoque exegético del segmento del precepto citado lleva en primer término a puntualizar desde una dimensión genérica que tales actividades de alcance intemacional o gestiones internacionales de las provincias, resultan legitimadas a partir de una percepción flexible de las "relaciones internacionales", cuya conducción y responsabilidad -como es de sobra conocidorecaen exclusivamente en el Estado Federal en cuanto a lo que corporizaría el "núcleo duro" de aquellas relaciones.

Correlativamente, la mencionada laxitud interpretativa de dicha expresión permitiria pensar en un "núcleo blando" que habilita la realización de actividades de tenor internacional por parte de los entes subestatales, o lo que por ejemplo y mutatis mutand, la doctrina italiana denomina "attività pro. mozionali" ("actividades de promoción exterior"), encaminadas justamente a la promoción del desamollo económico, social y cultural que las regiones pueden desempeñar con acuerdo del Gobierno ${ }^{37}$ (en el caso argentino, las provincias lo deben hacer "con conocimiento del Congreso Nacional").

Dicho en palabras de CASANOVAS y LA ROSA, al margen de las "relaciones internacionales" en sentido estricto y de la celebración de tratados internacionales, cabe "articular un

37 Agostin, Maria Valeria, "Lineas de evolución de la acción de las regiones italianas en el exterior y de su participación en el proceso de adopción de decisiones comunitarias", en AA.VV., "La acción exterior y comunitaria de los Länder, regiones, cantones y comunidades autónomas", cit., p. 24. 
ámbito de acción exterior que se fundamente en los poderes e intereses propios de las entidades infraestatales y se ajuste a lo que es la práctica constitucional e internacional actual en los Estados de estructura compleja" 38 .

Aclarado lo anterior, y retomando en particular el tramo del art. 124 referido a las actividades que ad extra están facultadas a llevar adelante las provincias, la terminologia "convenios internacionales" que pueden celebrar, suponemos ha sido pensada para transmitir un mensaje que exteriorice una distinción categorial entaizada en una valencia juridica más tenue y menos formal que la de "tratados internacionales", que quedan inmersos -estos últimos- en la órbita competencial exclusiva del Estado Nacional en el manejo de las relaciones internacionales ${ }^{39}$ ("núcleo duro").

Justamente, la celebración de "convenios internacionales" por las unidades provinciales queda supeditada a la compatibilidad "con la política exterior de la Nación" y la no afectación de "las facultades delegadas al Gobierno federal o al crédito público de la Nación". Puede acordar-

Casanovas y La Rosa, Oriol, "La acción exterior de las Comunidades Autónomas y su participación en la celebración de tratados internacionales", loc, cit, en nota anterior, pp. 57/58.

59. En general hay consenso doctrinario acerca de que, en el contexto de nuestra Ley Fundamental e interpretando la voluntad del constituyente reformador, la expresión "convenios internacionales" representa un escalón jerárquico inferior a la de "tratados internacionales", reservados al Estado Nacional (Poderes Ejecutivo y Legislativo) en el marco de una fórmula léxica empleada por ejemplo en los arts. 27,31 y 75 , ines. 22,23 y 24.

Sin embargo, es preciso recordar que desde un plano genérico y en el ámbito del derecho internacional, entre ambas denominaciones existen lazos de afinidad semántica. Es que la Convención de Viena sobre el Derecho de los Tratados, de 23 de mavo de 1969, que entrara en vigor el 27 de enero de 1980, ha determinado que a los efectos de tal Convención, "se entiende por 'rratado' un acuerdo internacional celebrado por escrito entre Estados y regido por el derecho internacional, ya conste en un instrumento único o en dos o más instrumentos conexos y cualquiera que sea su denominación particular" (cfr. art. 2.1'a').

Al explicar la cirada definición, DE LA GUARDIA puntualiza que segün tal Convención y a los efectos de su texto, 'todo convenio será un 'tratado' siempre que: a) sea un acuerdo internacional; b) haya sido celebrado por escrito; c) se haya concluido entre Estados; d) esté regido por el derecho internacional, y e) cualquiera sea su denominación particular y aunque conste en un instrumento único o en dos o más instrumentos conexos" (DE LA GLARDIA, Ernesto, Derecho de los tratados internacionales, Buenos Aires: Edit. Ábaco, 1997, p. 107). Justamente al desarrollar este último elemento de la definición, es decir, "cualquiera sea su denominación particular y aunque conste en un instrumento único o en dos o más instrumentos conexos", el citado autor recuerda que la Convención adhiere al criterio contemporáneo y generalizado en cuanto a la utilización del término "tratado", que abarca a "todos los acuerdos internacionales, sobre los que existe una gran variedad de denominaciones, como convención, protocolo, arreglo, declaración, carta, pacto, convenio, acta, acuerdo, estaturo, concordato, canje de notas, notas reversales, minutas aprobadas, memorándum de acuerdo, modus vivendi, etcétera" (ibid., pp. 114/115).

Por su parte, en el ámbito del derecho comparado latinoamericano existen Constituciones que plasman en sus textos las nomenclaturas "tratados o convenios internacionales", por ejemplo, las de Bolivia y Ecuador (sobre el particular, ver el libro de BazAN, Victor, Jurisdicción constitucional y control de constitucionalidad de los tratados internacionales. Una vision de derecho comparado. México: Edit. Porrúa, D.F., 2003). 
se o no con los lineamentos léxicos adoptados por el constituyente reformador de 1994 para trazar los límites a las actividades provinciales de alcance internacional, mas lo que si queda claro es que en tal diseño lingüistico se inserta la matriz del citado principio de "lealtad constitucional", que en el particular las provincias deben acatar para preservar la intangibilidad del reparto de competencias acordado con el Estado Nacional.

En definitiva, y en lo que hace al objeto de tales "convenios internacionales", parece claro que el mismo debe girar en torno a competencias exclusivas de las provincias o concurrentes con la Nación.

Por su parte, no menor polémica trae consigo la fórmula escogida en punto a que tanto la creación de regiones como la celebración de convenios internacionales deben realizarse "con conocimiento del Congreso Nacional".

Liminarmente, nos apresuramos a aclarar que, desde nuestra óptica, "conocimiento" no origina la exigencia de consentimiento, aprobación ni autorización, sino de comunicación al Poder Legislativo.

Tal posición reconoce varios puntos de sustentación: en primer lugar, por cuanto desde el plano semántico "con conocimiento" solo supone el resultado de "hacer saber" o "informar", lo que dista conceptualmente de "consentimiento", "aprobación" u otros términos equivalentes; en segundo lugar, porque durante los trabajos y debates de la Convención Constituyente se manejaron varias opciones terminológicas para la redacción de este tramo de la norma en cuestión, entre los que se cuentan los mencionados en último término, decantándose finalmente por la expresión "con conocimiento", que -reiteramos- exhibe una carga de significado distinta de las enunciadas, además de que no cabe predicar de los constituyentes una actuación desprevenida o inopinada en la selección del texto particular; y, por último, refuerza nuestra percepción el distanciamiento que en el punto sẹ da en relación con la Constitución de EE.UU, una de las fuentes de la Ley Fundamental argentina, que exige el "consentimiento" del Congreso para que el Estado celebre convenio o pacto alguno con otro Estado o con una potencia extranjera $^{40}$ (art. I, Sección X, ap. 3).

Cuestión complicada es predeterminar qué sucederia en caso de que el Congreso estuviera en disconformidad con el acuerdo regional o que el convenio internacional violara los limites

40. La norma en cuestión, refiriéndose al ap. 2 del mismo articulo, expresa que sin el "consentimiento" del Congreso "ningún Estado podrá (...) celebrar convenio o pacto alguno con otro Estado o con una potencia extranjera" (el texto en español ha sido consultado en Cascajo Castro, José Luís y Garcla Átvarez, Manuel [editores], Constituciones extranjeras contemporáneas, 37 ed., Madrid: Tecnos, 1994, p. 68). 
impuestos constitucionalmente. En tales hipótesis, y siempre que las vias previas del diálogo democrático fracasaren, cabria al Estado Nacional la articulación de una acción judicial ante la Corte Suprema de Justicia en contra de las provincias (o la CABA) actuantes o, en un supuesto extremo y si eventualmente quedarán reunidas las pautas diseñadas por el art. 6 de la Constitución, disponer la intervención federal (arts. 75, inc. 31, ó 99, inc. 20, ibid.), en cuyo caso, GeL.. sugiere que los senadores representantes de las provincias en cuestión o de la CABA, deberian defender "las razones y justificación de los Estados locales" (énfasis del original) ${ }^{41}$.

Apoyándose en FríAs, HiERNÁNDE $Z^{42}$ advierte que un pronunciamiento negativo del Congreso no dejaría sin efecto el acuerdo, como sería el caso de la desaprobación.

Finalmente, y para aventar posibles cuestionamientos en el despliegue de la acción exterior de las provincias, ZARZA MENSAQUE ofrece como alternativa que por medio de un acuerdo previo entre el Estado Federal y aquellas, "el Congreso dicte una ley convenio que establezca los aspectos sustanciales y procedimentales que deben respetar los Estados locales para que los convenios que suscriban sean válidos" ${ }^{43}$.

C) ¿Una protección adicional para el federalismo en los procesos de integración?

Es importante destacar que durante los debates de la Convención Constituyente de 1994, que deparara el texto actualmente vigente, se planteó la incorporación de una especie de "cláusula federal" dirigida a proteger al federalismo frente a los tratados internacionales en materia de integración.

Justamente se postulaba que en la norma contenida en el hoy art. 75 , inc. 24 , párr. inicial, además del respeto por el orden democrático y los derechos humanos como príncipios por preservar en los tratados de integración que deleguen competencias y jurisdicción a organizaciones supraestatales, se incluyera al "sistema federal" asegurando a las provincias la efectiva participación en la decisión de los asuntos que las afectasen directamente.

La fundamentación de la moción puede ser sintetizada siguiendo las palabras del convencional Gabriel LLANO, cuando afirmaba que en el nuevo inciso que se pretendia agregar al entonces art. 67 (hoy 75) existia una omisión, "porque al Congreso Nacional se lo va a facultar a delegar competencias, pero en esa delegación de competencias se tiene que respetar el ámbito

41) Gelu, Maria Angêlica, op, cit., p. 863.

42 Frlas, Pedro J., Derecho Püblico Protincial, Depalma, Buenos Aires, 1987, p. 104; aludido por Hernandez (h.), Antonio M., Integración y globalización: rol de las regiones, protincias y municipios, cit., p. 44.

43 ZaRZA MenSAQUe, Alberto, "Las provincias en las relaciones interjurisdiccionales", en DRNAS DE ClemENT, Zlata y Rey CARO, Ernesto (Directores), Jomadas de reflexión sobre regionalización y Mercosur, cit., p. 59. 
de competencia reservado a las provincias" 4 . Anadia que "si van a existir por ahi organismos supranacionales con facultades de dictar normas obligatorias que van a tener una validez superior a nuestras leyes y que seguramente tendrán contenido económico y si estas normas van a tener una decisiva incidencia en el desarrollo de algunas economias regionales, yo creo que hay que completar esta norma con el respeto al sistema federal de gobierno. Es más, me animaría a proponer que haga alusión a la efectiva participación de las provincias" 45 . Asi, y luego de aludir a la experiencia alemana de los Lander por medio de los observadores, propuso completar la regla de la siguiente manera: "y que respete los derechos humanos, el orden democrático, el sistema federal a través de la efectiva participación de las provincias en dichos organismos" ${ }^{\text {"46 }}$ (el remarcado no es del original).

Finalmente la propuesta no prosperó, manifestándose para descartarla que el modelo constitucional argentino cuenta con las reservas realizadas y prescriptas en la Constitución para sostener su sistema federal, por lo que se entiende que la aprobación por las distintas instancias federales, como es el caso de la Cámara de Senadores, que requerirá una mayoría calificada para tratar estos temas, cubriria las necesidades que las provincias reclamen durante un proceso de integración ${ }^{47}$.

Sea como fuera y más allá de no haber fructificado la aludida proposición -lo que para algún sector de la doctrina es una muestra más del déficit federal de la reforma constitucional ${ }^{48}$-, es interesante la reflexión de SABSAY cuando afirma que la circunstancia de que el constituyente haya apostado por un modelo federal de concertación que ubica al pais en camino hacia el fortalecimiento de la periferia para reequilibrar el excesivo vigor que han acusado las fuerzas centripetas en la historia de nuestro federalismo, hara "posible contrarrestar-igualmente- la excesiva concentración de poder que puede resultar del proceso de integración continental que hemos inau-

44 "Versiones taquigráficas de la Comisión de Redacción", Obra de la Contención Nacional Constituyente 1994, T" IV, Buenos Aires: Centro de Estudios Juridicos y Sociales, Ministerio de Justicia de la Nación, La Ley, 1997, p. 4144.

45. Idem.

to Ídem.

47 Cfr. Dalla VIA, Alberto R., Manual de derecho constitucional, Lexis Nexis, Buenos Aires, 2004, p. 688, quien aclara que las objeciones fueron respondidas en los términos indicados en el texto al que se refiere esta nota por el convencional Juan Pablo Cafiero, miembro informante de la Comisión de Integración y Tratados Internacionales.

Sobre el tema de la protección del federalismo frente a los tratados internacionales en materia de integración y lo que denomina "el limite federal de la supranacionalización", puede consultarse Farrando (h.), Ismael, "El municipio en la perspectiva de la integración", en Pérez Gull.hou, Dardo et. al., Derecho Püblico Provincial y Municipal, Vol. I, 2" ed. actualiz., particularmente pp. 356/357 y nota 23.

48 Vid, en ese sentido, por ejemplo, Castorina de TArqunn, Maria Celia, "El federalismo", loc. cit. en la última parte de la nota anterior, pp. 138/141. 
gurado junto a las naciones limitrofes" $"$ "énfasis agregado); aunque no deja de advertir que tales comentarios se circunscriben a la descripción de las disposiciones constitucionales y no a las experiencias en materia de aplicación pues "más allả de las aspiraciones del constituyente, la labor legislativa no las ha acompañado" 30 .

Por nuestra parte sólo nos permitimos acotar que en éste como en otros puntos temáticos, la hora actual impone como desafio impostergable la revitalización del Senado para la asunción y el cumplimiento genuinos de su rol como Cámara de representación de los intereses de las provincias en nuestro esquema estatal federal ${ }^{51}$, tanto en relación con el plano internacional como en la dimensión endógena ${ }^{52}$.

D) ¿Y los municipios?

Naturalmente, los municipios no pueden quedar al margen del proceso integrativo $\mathrm{y}$, a

49 Sabsay, Daniel Alberto, "El federalismo en la Constitución y las posibilidades de reconstrucción que brinda la reforma de 1994", en AA.VV., Constitución de la Nación Argentina. Con motivo del sesquicentenario de su sanción, T 11, Santa Fe: Asociación Argentina de Derecho Constitucional, 2003, p. 375.

30. Idem.

54 Mutatis mutandi y concentrándose en el caso de México pero con utilidad genérica, al tratar el tema del poder de celebrar tratados internacionales y su vinculación con el sistema federal, SERNA DE LA GARZA plantea la conveniencia de redefinir el diseño básico del poder de celebración de tales instrumentos, uno de cuyos puntos esenciales tiene que ver con la "revitalización del Senado como camara de representación de los estados", estableciéndose en el sistema de distribución de competencias la existencia y eficacia de controles sobre la decisión politica del presidente de celebrar un tratado que recaiga sobre materias reservadas a las entidades federativas. En ese punto, el autor citado postula la necesidad de pensar en "un Senado que, una vez revitalizado como cámara federal, pudiese intervenir en el proceso de celebración de tratados internacionales, pero desde la negociación misma del instrumento", y no solo como instancia de aprobación o rechazo de un documento que fuera negociado exclusivamente por el Ejecutivo federal.

Concluye aseverando que "un Senado erigido en una verdadera cámara de representación de los intereses de los estados es la mejor garantia de que los tratados internacionales celebrados por el presidente de la República no afecten de manera adversa a las partes integrantes del pacto federal (SERNA DE LA GARZA, José Maria, "La lógica centralizadora del sistema federal mexicano", en VALADÉs, Diego y SERNA DE LA GARZA, José Maria [coordinadores], Federalismo y regionalismo, México, D.F.: Universidad Nacional Autỏnoma de México [Instituto de Investigaciones Juridicas] y Tribunal Superior de Justicia del Estado de Puebla, 2005, pp. 578/582).

32 Baste recordar que, por ejemplo, en materia de coparticipación federal impositiva -uno de los temas ligados al "fortalecimiento del federalismo" pregonado por la Ley 24.309 declaratoria de la necesidad de la reforma constitucional de 1994, y reivindicados en su oportunidad como logros de esta- se hace perceptible la brecha entre lo pautado normativamente y las pretericiones en el ámbito fáctico, ya que tanto el régimen coparticipativo (a instrumentarse por una ley convenio con el Senado como Càmara de origen), como la reglamentación del organismo fiscal federal aludidos por el art. 75, inc. 2, debieron haber sido establecidos antes de la finalización del año 1996, de acuerdo con la disposición transitoria sexta, lo que aún no ha ocurrido.

No es precisamente agradable constatarlo ni decirlo, pero es igualmente dificil disimular que la sombra de las omisiones inconstitucionales traducibles en la falta de desarrollo legislativo de varios aspectos contenidos en la letra de la Constitución, continúa siendo frondosa en el escenario juridico nacional. 
partir de la autonomia que les reconoce explicitamente la Ley Fundamental en el art. 123, pueden desplegar actividades de gestión internacional, observando ciertos limites entre los que se cuentan los impuestos por la Constitución de la provincia a la que pertenecen y naturalmente los fijados por la Norma Superior de la Nación.

En tal sentido, y si bien es cierto que la Carta Magna no depara expresamente a los municipios una norma equivalente al art. 124 respecto de las provincias, BARRERA BUtELER advierte que el contexto social del mundo globalizado impone considerar que también la atribución de celebrar acuerdos en el orden internacional queda comprendida en el principio constitucional de autonomia municipal pues el ámbito de interrelación e interdependencia que condujo al reconocimiento de tal atribuciỏn a las provincias (aun antes de la reforma de 1994), apunta a la misma dirección respecto de los municipios, que tienen múltiples vínculos convencionales en el plano internacional, por ejemplo, la práctica reirerada de los "hermanamientos de ciudades", que vinculan con lazos de cooperación reciproca a municipios de diversos paises y continentes ${ }^{53}$.

\section{La experiencia europea}

Abandonando el marco del derecho argentino, emprenderemos un breve recorrido por la experiencia europea, limitándonos a presentar algunas posibilidades de participación de las colectividades territoriales en la dinámica supranacional y a enfocar cuestiones delicadas que surgen del impacto de esta en los Estados con estructura compleja (regional, federal, federo-regional o con incipientes signos centrifugos), a partir del afianzamiento del esquema comunitario, de un lado, y del crecimiento del número de Estados que procuran acrecentar sus procesos de descentralización ad intra, por el otro.

A) Participación de las colectividades territoriales en el proceso comunitario.

Ligado a lo que anticipábamos, en la praxis integrativa europea existen Estados con una normativa avanzada en materia de participación regional, tal como resalta Perez González, quien cita el caso de Bélgica (devenida en época relativamente reciente en Estado federal), donde los entes federados participan activamente en la política comunitaria que lleva a cabo el Estado, plasmándose en 1993 una nueva reglamentación constitucional y legal de las relaciones internacionales de las comunidades y regiones belgas ${ }^{54}$.

5) Barrera Buteler, Guillermo, "Facultades de las entidades subnacionales en la celebración de gestiones y convenios internacionales", en Hernández (h.), Antonio M. (Director), La descentralización del poder en el Estado contemporáneo, cit., pp. 213/214.

54 Pérez Gonzátez, Manuel, "Facultades de los entes subnacionales en el sistema comunitario europeo", en Drnas DE CIEMENT, Zlata y REY CARO, Ernesto (Directores), Jornadas de reflexión sobre regionalización y Mercosur, cit., p. 21. 
Sin abandonar los contornos de Europa, se aprecia que no todos los Estados resuelven de idéntico modo la participación de las entidades subestatales en las mencionadas fases ascendente $y$ descendente, pues algunas ponen el acento en aquélla y otros en esta.

Así, en Alemania, a partir de la suscripción del Pacto de Lindau de 1957, los Länder (Estados miembros del Estado federal) participan en la etapa ascendente de la celebración de los tratados internacionales que pueden afectar su competencia o intereses ${ }^{55}$. Cuando solo concierne a estos, el Bund (poder central) está obligado a escuchar el parecer regional, pero si ya el tratado atañe sustancialmente a las competencias exclusivas, la opinión de los Länder debe ser tenida en cuenta de forma determinante por el Bund al momento de celebrar el tratado en cuestión ${ }^{56}$. Por su parte, debe además computarse la figura del Ländersbeobachter (observadores de los Länder), que participa como miembro de la delegación alemana al Consejo de Ministros en las sesiones que aborden temas que afecten a aquéllos.

Una situación similar, aunque con sus propias particularidades, se da también en Austria, donde -como recuerda Pérez González- con motivo de su ingreso a la UE se modificó la Constitución Federal estableciendo un acuerdo entre la Federación y los Länder y municipios en asuntos de integración europea, que permite un modelo de participación regional en cuestiones atingentes al ámbito de acción autónoma de los Länder o sea susceptibles de afectar sus intereses, previendo la posibilidad de que ellos den un parecer conjunto sobre cualquier materia perteneciente a su competencia legislativa, asi como la posibilidad de que los mismos envien representantes a las negociaciones que versen sobre materias que en el plano interno sean de su competencia exclusiva o que conciernan a sus intereses ${ }^{57}$.

A su turno, el sistema italiano atiende preferentemente a la fase descendente de aplicación de los actos comunitarios dentro del Estado, fijándose normativamente una serie de pautas que debe seguir el poder central para la aplicación del derecho comunitario en las regiones ${ }^{58}$, tema que retomaremos con más detalle en el subapartado inmediatamente siguiente.

En esta faz descendente, y entre otros puntos de interés, emerge un interesante aspecto de la cuestión. Radica en que en el marco comunitario una via importante de formación de su

35. Ibid., p. 20 .

5 idem.

57 Perez Gonzaifz, Manuel, "Ponencia de sintesis: 'La acción exterior y comunitaria de los Lünder, regiones, cantones y comunidades autónomas; un ensayo de recapitulación", en AA.VV., "La acción exterior y comunitaria de los Lünder, regiones, cantones y comunidades autónomas", cit., pp. 335/336.

58 Pérez Gonzalez, Manuel, "Facultades de los entes subnacionales en el sistema comunitario europeo", en DrNas DE CLEMENT, Zlata y REY CARO, Ernesto (Directores), Jomadas de reflexión sobre regionalización y Mercosur, cit., p. 21. 
normativa es la de las "directivas", que en palabras de PUENTE EGIDO, constituyen una categoria especial normativa con las que, en aplicación de la técnica de las "leyes marco", la disposición comunitaria deja una amplia labor de desarrollo a los órganos legislativos internos de los Estados, que les permiten -siempre que se respeten las lineas centrales que fija- normas singulares adaptadas a las particularidades de cada país ${ }^{59}$.

Y es justamente en este ámbito de desarrollo del derecho comunitario ad intra donde los entes infraestatales pueden tener protagonismo, cuestión que -como ha ocurrido en España ${ }^{60}$ - tal vez podria generarles algún conflicto competencial con el Estado central, aunque lo ideal sería que tales inconvenientes sean evitados o resueltos a partir de la pauta de "confianza o lealtad federal" y en un deseable marco de cooperación entre ambos estamentos politicos ${ }^{6 !}$.

Como fórmula sintetizadora de las vias de participación de las entidades subnacionales en los procesos de adopción de decisiones en la estructura comunitaria europea sobre materias de competencia de aquéllas o susceptibles de afectar sus intereses, que se han vertebrado en Eu-

59. PUENTE EGIDO, José, op, cit., p. 1651.

so PuEntE EgIDo revela varios casos resueltos por el Tribunal Constitucional español en los que respectivamente se expidió a favor de la competencia preferente del Estado Central aunque sin excluir por completo la participación de las Comunidades Autónomas (STC, de 20 de diciembre de 1988 [Pleno], N 598 y $1.403 / 1986$ y $857 / 1988$ (acumulados]), o a favor de estas mas sin excluir del todo la competencia del Estado Central (STC, de 29 de ocrubre de 1992, Recurso de Inconstitucionalidad N 1.314/1986 y STC, de 8 de enero de 1983 [Pleno], $\mathrm{N}^{\circ} 1.043 / 1986$ y $336 / 1987$ ). El citado autor analiza el tema desde la perspectiva del efecto mutante que en la Constitución interna de cada Estado Miembro puede tener la aplicación y el desarrollo del derecho comunitario en el orden juridico de cada Estado, preguntándose en el caso español si por la acción general del derecho comunitario las mismas categorias juridicas con las que fue elaborado el derecho constitucional español vigente no pueden y hasta deben ser reelaboradas, poniendo como ejemplo la noción de "competencia exclusiva" tanto en el Estado como en las Comunidades Autónomas, concluyendo que la "que en la Constitución o en los Estatutos [de Autonomia] fue pensada como 'verdaderamente exclusiva', el Tribunal Constitucional tiende cada vez más a interpretarla en determinadas circunstancias como competencia compartida" (cfr. PUENTE EGiDO, José, op. cit., pp. $1659 / 1665$ y 1651 ).

6) CASTORINA dE TARQUINi señala que en el proceso del Mercosur se deberá proceder con cautela y privilegiar la participación y el control provinciales, objetivo que necesitará previamente que los intérpretes del federalismo desarrollen sus relaciones sobre la base de ciertos presupuestos que surgen de nuestro derecho y que, redimensionados, deberàn incorporarse al comunitario. En ese contexto, ubica a los principios de lealtad federal y de garantia federal. En la visión de la autora, el primero de ellos importa de parte del gobierno central y de los gobiernos locales un comportamiento encaminado al mantenimiento de la unión, debiendo el gobierno nacional abstenerse de toda medida que lesione o restrinja los intereses provinciales, los que a su vez colaboraràn en la consolidación de la unión nacional; mientras que el segundo de aquellos supone un derecho y un deber reciprocos y correlativos entre los Estados locales y el nacional: este tiene el derecho de mantener su integridad y el deber de preservar la de los Estados miembros, los que a su vez tienen el deber de consolidar la unión, condición de su propia existencia, y el derecho a que ésta les sea reconocida y respetada (CAsTORINA DE TARQuinı, Maria Celia, Federalismo e integración, Buenos Aires: Instituto Argentino de Estudios Constitucionales y Politicos, Ediar, 1997, pp. 70/77). 
ropa en diversos Estados Miembros politicamente descentralizados, Pérez GonzÁlez distingue entre participación directa, que supone la presencia de representantes regionales en instituciones u órganos de la UE, e indirecta, que incluye diversos mecanismos internos para influir en la posición que ante aquéllas asuma el Estado ${ }^{62}$.

B) Responsabilidad internacional del Estado por acciones y omisiones de las entidades in. fraestatales

Tampoco cabe soslayar otra importante faceta del problema: la responsabilidad internacional o comunitaria del Estado por los hechos u omisiones cometidos por los entes territoriales subestatales en violación de obligaciones precisamente internacionales o comunitarias asumidas por aquél.

Mutatis mutandi, el problema reconduce a un principio general que marca que desde el prisma del derecho internacional todo Estado es libre de escoger su modelo de configuración estadual y su sistema interno de organización territorial, lo que supone una premisa iusinternacional de respeto por la autoorganización intraestatal derivada de la soberania del Estado que surge de su condición de sujeto del ordenamiento internacional y del principio de no intervención en asuntos internos ${ }^{63}$.

Es que, como recuerda MANGias Martin, dada la unidad del Estado para el derecho internacional, las conductas de sus órganos y de sus entidades territoriales se atribuyen al Estado y, en el caso de violación de una obligación internacional o comunitaria de este, el hecho ilícito internacional de la entidad territorial o del órgano estatal en cuestión será considerado como hecho del Estado susceptible de generar la responsabilidad internacional de este ${ }^{64}$.

Como conclusión provisional debe por ende concederse que el incumplimiento de las obligaciones comunitarias en que incurran regiones, provincias, comunidades autónomas, etc., en principio vincula y compromete internacionalmente al Estado Miembro, sin perjuicio de las medidas que en ejercicio de sus atribuciones constitucionales pudiera éste emprender en el ámbito interno contra aquellas entidades subestatales por violación del principio de lealtad constitucional y el incumplimiento del derecho comunitario.

62 Pérez González, Manuel, "Ponencia de síntesis; 'La acción exterior y comunitaria de los Länder, regiones, cantones y comunidades autónomas: un ensayo de recapitulación'”, en AA.VV., "La acción exterior y comunitaria de los Lüder, regiones, cantones y comunidades autónomas", cit., p. 333.

6) Mangas Martin, Araceli, "La ejecución del derecho comunitario por las Comunidades Autónomas: la jurisprudencia del Tribunal de Justicia de las Comunidades Europeas", en AA.VV., Comunidades Autónomas y Comunidad Europea. Relaciones juridico-institucionales, Valladolid: Cortes de Castilla y León, 1991, p. 183.

(H) Idem. 
Naturalmente, tal respuesta deja espacio para la duda puesto que si bajo el manto de la autonomia surgente del federalismo las instituciones subnacionales exigen una mayor participación en las fases ascendente y/o descendente, ello supone un correlativo agravamiento del nivel de responsabilidad propia derivada de aquel requerimiento de obtener mayor dosis de protagonismo en el proceso.

La dubitación referida tiene alguna consistencia aunque por lo pronto la "indiferencia" del derecho comunitario por la estructura constitucional interna ${ }^{65}$ de los Estados Miembros de la estructura comunitaria pareciera apuntar precisamente a obturar de modo preventivo una atomización del nivel de respuesta que haria decaer el tenor de efectividad de tal responsabilidad primariamente en cabeza de los Estados por incumplimiento de las obligaciones asumidas en la órbita comunitaria. Por lo demás, aunque obvio, es ciertamente imprescindible recordar que la responsabilidad de la provincia, región, comunidad autónoma, etc., en el contexto internacional solo podria existir en tanto y en cuanto se les haya reconocido personalidad o subjetividad intemacionales, presupuesto para viabilizar la responsabilidad emergente de sus acciones y omisiones en tal esfera.

Sin embargo, lo expuesto hasta aqui en modo alguno excluye el emprendimiento conjunto de soluciones de carácter preventivo, lo que supone la coparticipación del poder central y de las entidades infraestatales cuando se trate de la asunción de obligaciones internacionales vinculadas a competencias en cabeza de estos entes y no del Estado, lo que en las certeras palabras de REMIRo Brotons colocaria a este en una situación lamentable, "chocando hacia afuera con quien le exige el cumplimiento y hacia adentro con quien, siendo el titular de la competencia, se excusa para incumplirla alegando que al no haber intervenido en el proceso de elaboración nadie le puede imponer un hecho consumado" $"$.

En esta lógica, tampoco debe soslayarse el marco que proporciona el principio de "cooperación leal" entre la estructura comunitaria y los Estados Miembros, en punto a respetarse y asistirse mutuamente en el cumplimiento de las misiones derivadas del respectivo tratado institutivo $^{67}$. De tal premisa, entre otras cuestiones, deriva la obligación de los Estados de adoptar

65. Tomamos la expresión relativa a la "indiferencia del derecho comunitario por la estructura constitucional interna de los Estados Miembros" de Mangas Martin, Araceli, ibid., p. 185.

of Remiro Brotons, Antonio, "La responsabilidad por incumplimiento de las comunidades autónomas. Posibles soluciones", en AA.VV., Comunidades Autónomas y Comunidad Europea. Relaciones juridicoinstitucionales, cit., p. 211.

6. Las notas para conceptuar al principio de "cooperación leal" fueron tomadas del art. 1.5 del Tratado de Lisboa, que -como veremos in exterso más adelante- sustiruye al Tratado por el que se establece una Constitución para Europa y modifica principalmente el Tratado de la Unión Europea (TUE) y el Tratado Constirutivo de la Comunidad Europea (TCE). Por conducto de dicha norma se inserta al TUE el art. 3 bis, en cuyo ap. 3 se efectúa la referencia especifica a la mencionada pauta de "cooperación leal" y sus implicancias. 
todas las medidas generales o particulares apropiadas para asegurar el cumplimiento de las obligaciones surgentes del tratado en cuestión o de los actos de las instituciones comunitarias.

\section{ACERCA DE DETERMINADAS INSTANCIAS DE VINCULACIÓN Y PARTICI- PACIÓN DE LAS ENTIDADES INFRAESTATALES EN LA EXPERIENCIA COMUNI- TARIA EUROPEA}

En una doble dimensión, visualizando de un lado las regiones europeas y, del otro, las ciudades frente a la experiencia comunitaria europea, presentaremos sumariamente dos instancias que, aunque diversas, tienen propósitos convergentes: el "Comité de las Regiones" y "Eurocities".

\section{El Comité de las Regiones ${ }^{68}$}
A) Gẻnesis
El Comité de las Regiones (en adelante, también el Comité) fue creado en 1992 en el Trata- do de Maastricht y comenzó a funcionar en 1994.

Como se ha sostenido, su implementación respondió a la necesidad de afrontar dos temáticas centrales: en primer lugar, la constatación de que gran parte de la normativa comunitaria se aplica en los niveles local o regional, de lo que se desprende claramente la importancia de que representantes de estas participen en la elaboración de dicha normativa; $y$, en segundo lugar, se temia que la Unión Europea evolucionara dejando de lado a los ciudadanos, es decir, de espaldas a estos, por lo que se reparó en la conveniencia de incorporar al proceso comunitario a los estamentos gubernamentales más próximos a aquellos.

La implementación del Comité por el Tratado de Maastricht se inscribe en un contexto de mayor calado, pues supuso el reconocimiento del fenómeno "regional" por parte del Tratado de la Unión Europea (TUE) luego de que los tratados constitutivos de las Comunidades Europeas lo ignoraran abiertamente. Esa "sensibilidad" ante la cuestión regional, además de la creación del Comité, se plasmó -al menos- en otros dos importantes aspectos: a) permitió la participación de autoridades regionales en el Consejo; y b) instituyó el principio de subsidiariedad, tema éste que nos tiende el puente hacia el punto que abordaremos a continuación ${ }^{69}$.

68. Algunos de los datos referidos en este segmento del texto fueron extraidos de: http://europa.eu/scadplus/glossary/committee_regions_es.htm y de http://europa.eu/scadplus/glossary/subsidiarity_es.htm.

*9 Cftar. Fernandez Segado, Francisco, en el documentado ensayo "Las Comunidades Autónomas ante las relaciones internacionales: un paradigma del dinamismo evolutivo del Estado autonómico español", en VALADES, Diego y SERNA DE LA GARZA, José Maria (coordinadores), Federalismo y regionalismo, cit., p. 370. 
B) Composición y naturaleza del Comité. Los principios de subsidiariedad y proporcionalidad

Está compuesto por 344 representantes de las comunidades locales y regionales, designados por un periodo de cuatro años por el Consejo. Debe recordarse que el Tratado de Niza, adoptado en diciembre de 2000, no modificó el número ni la distribución de los escaños por Estado Miembro en el Comité, aunque fijó como tope máximo de miembros de este la cantidad de 350. A su turno, el proyecto de Tratado por el que se establecia una Constitución para Europa (hoy sustituido por el Tratado de Lisboa -en adelante, también TL-), previó llevar el mandato de los integrantes del Comité de cuatro a cinco años, lo que el TL mantuvo.

El Comité es básicamente un órgano consultivo de la Unión Europea, aunque con vocación políti. $\mathrm{ca}^{70}$, que permite a los entes territoriales hacer oir su voz en el proceso decisorio comunitario.

Una aproximación taxonómica para catalogar tales competencias consultivas, puede vertebrarse del siguiente modo: a) dictámenes de carácter preceptivo en las siguientes materias: educación; cultura; salud pública; redes transeuropeas de transporte; cohesión económica y social (todos estos campos temáticos ya competian al Comité antes del Tratado de Ámsterdam); politica común de transportes; empleo; politica social; Fondo Social Europeo; formación profesional y juventud; y medio ambiente (estos asuntos fueron añadidos por dicho Tratado); b) consultas facultativas (discrecionales) que pueden dirigirle el Consejo, la Comisión y el Parlamento Europeo; y c) dictámenes que 'motu proprio' pruede elaborar el Comité.

Paralelamente, su rol politico consiste en facilitar la mejor aplicación de los principios de subsidiariedad y proporcionalidad en la Unión Europea.

En otro plano, el principio de subsidiariedad puede caracterizarse como aquel que tiene por objeto garantizar que las decisiones se tomen lo más cerca posible del ciudadano, comprobándose constantemente que la acción que vaya a emprenderse a escala comunitaria se justifica en relación con las posibilidades que ofrecen los niveles nacional, regional o local. Concretamente, se trata de una premisa según la cual la Unión, salvo en sus ámbitos de competencia exclusiva, sólo interviene en la medida en que su acción sea más eficaz que una intervención en los marcos nacional, regional o local.

Al decir de LEGUINA, constituye un principio delimitador de competencias entre la Unión y los Estados Miembros y es la norma de reparto de tareas de la organización federal y uno de los

70 La afirmación en cuanto al desarrollo de competencias consultivas del Comité como "órgano con creciente vocación politica", corresponde a Moreno VazQuez, Manuel, Comité de las Regiones y Unión Europea, Valencia: Polo Europeo Jean Monnet, Universitat de València, Tirant lo Blanch, 2001, pp. 178 y ss. 
ejes de la arquitectura europea ${ }^{71}$, pugnando por que las decisiones políticas se adopten en el ámbito más próximo al ciudadano para lograr la mayor eficacia posible; además, está firmemente ligado a los principios de proporcionalidad y de necesidad, con arreglo a los cuales la acción de la Unión no debe exceder de lo necesario para alcanzar los objetivos del tratado institutivo.

Es preciso advertir que el mencionado proyecto de Tratado (que establecia una Constitución para Europa) preveia reforzar el citado principio de subsidiariedad, especialmente al obligar a las instituciones a mantener informados a los parlamentos nacionales durante todo el procedimiento legislativo. Asimismo, proyectaba implementar un mecanismo de "alerta rápida o temprana" ("Early Waming System") sobre el respeto del principio de subsidiariedad, que permitiria a los parlamentos nacionales solicitar a la Comisión el reestudio de una propuesta legislativa cuando estimen que ésta no se ajusta al mencionado principio.

Debe advertirse que el debate sobre la inclusión del procedimiento de "alerta rápida" no ha sido del todo pacifico, pues -entre otras razones- se lo objeta por constituir una forma de restar protagonismo al Parlamento Europeo por "la puerta pequeña", retardar la función legislativa de la UE y considerar como más que probable que los parlamentos nacionales lo aprovechen para hacer consideraciones que nada tengan que ver con la subsidiariedad ${ }^{72}$.

A tales ataques dialécticos se ha respondido que el mecanismo en cuestión supone simple y llanamente atribuir a los parlamentos nacionales la posibilidad de que se pronuncien sobre una cuestión que afecta directamente a los Estados y entes territoriales de estos en punto a que las normas que la Unión pretende aprobar aplica correctamente aquel principio y no invade competencias que no le son propias ${ }^{73}$; además, $y$ en cuanto a la tacha relativa a la posibilidad de abrir la puerta a que los parlamentos locales efectúen consideraciones desconectadas del problema de la subsidiariedad, se ha replicado que aunque ello sea cierto, no se trata en realidad de un problema, pues ya está la Comisión para desestimar los informes remitidos en esos términos, sino más bien de una via para seguir avanzando en el fortalecimiento democrático (agregamos por nuestra parte, para paliar en cierta medida el déficit de tal indole que se imputa a la UE) y de participación de los parlamentos de los Estados Miembros en las cuestiones comunitarias $^{74}$.

LEGUINA, Joaquin, "Intervención de apertura", en AA.VV., "La acción exterior y comunitaria de los Länder. regiones, cantones y comunidades autónomas", Vol. I, cit., pp. 16 y 18.

72 Ver la presentación de tales cuestionamientos en ARANDA ÁtvAREz, Elviro (quien se encarga de rebatirlos defendiendo el mecanismo de "alerta rápida"), en "El fortalecimiento de los parlamentos en la Unión Europea: la incorporación del Early Warning System", Teoria y Realidad Constitucional, $\mathrm{N}^{\circ} 15,1^{\text {tr }}$ semestre 2005, Universidad Nacional de Educación a Distancia, Madrid, 2004, pp. 292/293.

73 Ibid., p. 292.

it Ibid, p. 293. 
En el apartado siguiente abordaremos algunos aspectos adicionales de esta temática.

C) El Tratado de Lisboa, el Comité de las Regiones, la cohesión territorial y las autonomias regionales y locales

No puede dejar de mencionarse que el Consejo Europeo de 21 y 22 de junio de 2007 fue trascendente. En efecto, llamados el 23 de julio del mismo año a pronunciarse sobre el futuro de la Unión Europea, los Jefes de Estado y de Gobierno convinieron iniciar una Conferencia Intergubernamental para redactar un Tratado de reforma de los actuales instrumentos institutivos antes de la finalización de 2007.

Como consecuencia de ello, el jueves 13 de diciembre de 2007, aquéllos suscribieron el TL en el Monasterio de los Jerónimos de esta ciudad. Básicamente, dicho instrumento modificará los dos textos fundamentales de la Unión Europea: el TUE y el TCE, pasando este último a denominarse "Tratado de Funcionamiento de la Unión Europea"; además del Tratado constitutivo de la Comunidad Europea de la Energía Atómica, insertando asimismo un conjunto de protocolos.

El de Lisboa representa una versión edulcorada del Tratado por el que se establecia una Constitución para Europa (que naufragó tras la derrota de los referenda llevados a cabo en Francia y Holanda) y, sin mencionar la palabra "Constitución", busca acondicionar las instituciones comunitarias para adecuar su funcionamiento con los 27 Estados Miembros que hoy componen la UE. Los Jefes de Estado y de Gobierno de éstos se comprometieron en las conclusiones de su reunión a buscar una "ratificación rápida" del tratado, que se espera sea aprobada definitivamente antes del 31 de diciembre de 2008 para que entre en vigencia de cara a las elecciones al Parlamento Europeo de junio de 2009.

Al respecto, el art. 6 del TL establece que el mismo será ratificado por las Altas Partes Contratantes de conformidad con sus respectivas normas constitucionales (ap. 1) y entrará en vigor el 1 de enero de 2009, siempre que se hayan depositado todos los instrumentos de ratificación o, en su defecto, el primer dia del mes siguiente al del depósito del instrumento de ratificación del último Estado signatario que cumpla dicha formalidad (ap. 2).

En su introito el TL enuncia como propósitos genéricos a los siguientes: completar el proceso iniciado por los Tratados de Ámsterdam y Niza, a fin de reforzar la eficacia y la legitimidad democrática de la UE y mejorar la coherencia de su acción.

Cabe destacar que por el art. 1.4 del TL se modifica el art. 2 del TUE, en cuyo ap. 3, párr. $3^{\circ}$, en lo que atañe a los intereses de las entidades subestatales, se pone de manifiesto que la UE fomentará la cohesión económica, social y territorial (es decir, se complementa su objetivo de 
cohesión económica y social al hacerla extensiva al plano territorial) y la solidaridad entre los Estados Miembros; además, respetará la riqueza de su diversidad cultural y lingüistica (pảrr. $4^{\circ}$ ). Vinculado a lo que mencionábamos, de hecho se modifica el Protocolo sobre la cohesión económica y social, que pasa a llamarse Protocolo sobre la cohesión económica, social y territorial.

Mutatis mutandi, se ha puntualizado que el concepto de cohesión territorial va más allả de la idea de cohesión económica y social, ampliándola y reforzándola; asi, con aquella se pretende "ayudar a lograr un desarrollo más equilibrado reduciendo las disparidades existentes, impidiendo los desequilibrios territoriales y aumentando la coherencia tanto de las politicas sectoriales que tienen una repercusión territorial como de la política regional", para asimismo mejorar la integración territorial y fomentar la cooperación entre las regiones ${ }^{75}$.

Por su parte, el art. 1.5 del TL deroga el art. 3 del TUE e inserta el art. 3 bis, en cuyo ap. 2, y en lo que aqui interesa, estipula que "[l]a Unión respetará la igualdad de los Estados Miembros ante los Tratados ${ }^{76}$, asi como su identidad nacional, inherente a las estructuras fundamentales politicas y constitucionales de éstos, también en lo referente a la autonomia local y regional. (...)" -énfasis añadido-.

En relación con el Comité de las Regiones, por el art. 1.14 del TL atinente al Título III ("Disposiciones sobre las Instituciones") del TUE, el art. 9, ap. 4, de éste especifica que el Parlamento Europeo, el Consejo y la Comisión (algunas de las instituciones de la UE) estarán asistidos por un Comité Económico y Social y un Comité de las Regiones, que ejercerán funciones consultivas.

Una previsión homóloga se ubica en el capitulo relativo a los "Órganos consultivos de la Unión", particularmente en el ap. 1 del nuevo art. 256 bis del Tratado de Füncionamiento de la UE que se inserta. A su tiempo, en el ap. 3 de tal articulo se determina que este último Comité estará compuesto por representantes de los entes regionales y locales que sean titulares de un mandato electoral en un ente regional o local, o que tengan responsabilidad politica ante una asamblea elegida. Por último, el ap. 4 establece que los miembros del Comité no estarán vinculados por ningún mandato imperativo, ejerciendo sus funciones con plena independencia, en interés general de la Unión.

75. Cftar. Tercet informe sobre la cohesión económica y soctal, "Una nueva asociación para la cohesión. convergencia, competitividad y cooperación", Comisión Europea, COM (2004) 107 de 18 de febrero de 2004, Luxemburgo: Oficina de Publicaciones Oficiales de las Comunidades Europeas, impreso en Bélgica, 2004, p. 27.

76 En el art. 1, párr. $3^{\circ}$, del TUE (según la redacción diseñada por el art. 1.2.'b' del TL) se advierte que cuando en el texto se refiera a "los Tratados" hará referencia al propio TUE y al Tratado de Funcionamiento de la UE, aclarando que ambos tratados tienen el mismo valor jurídico, para luego establecer que la UE sustituirá y sucederả a la Comunidad Europea. 
Es especialmente significativa la cláusula que acuerda al Comité de las Regiones el derecho de recurso, para salvaguardar sus prerrogativas, ante el Tribunal de Justicia de la UE (cfr. art. 230, párr. $3^{\circ}$, del TCE, que proyecta modificar el art. 2.214.'b' del TL).

Ya en el ámbito del Protocolo sobre la aplicación de los principios de subsidiariedad y proporcionalidad $^{77}$ (uno de los que el TL identifica como los protocolos que deberán ir anejos al TUE, al Tratado de Funcionamiento de la UE y, en su caso, al Tratado constitutivo de la Comunidad Europea de la Energia Atómica), el art. 8 del citado Protocolo, luego de pautar que el Tribunal de Justicia de la UE será competente para pronunciarse sobre los recursos por violación del principio de subsidiariedad, por parte de un acto legislativo (párr. $1^{\circ}$ ), señala que el Comité de las Regiones - de conformidad con los procedimientos establecidos en el art. 230 del Tratado de Funcionamiento de la UE- también podrá interponer recursos contra actos legislativos para cuya adopción el Tratado nombrado en último término requiera su consulta (párr. $2^{\circ}$ ). De su lado, y en función del art. 9 del Protocolo que referenciamos, se especifica que la Comisión presentará al Consejo Europeo, al Parlamento Europeo, al Consejo y a los parlamentos nacionales un informe anual sobre la aplicación del art. 3 ter del TUE (referido a los príncipios de atribución, subsidiariedad y proporcionalidad aplicables a las competencias de la Unión y que sustituye al art. 5 del TCE); informe que deberá remitirse asimismo al Comité Económico y Social y al Comité de las Regiones.

Básicamente, en su art. 6 , párr. $1^{\circ}$, el mencionado protocolo contiene la facultad de todo parlamento nacional o de toda cámara de uno de esos parlamentos de dirigir a los Presidentes del Parlamento Europeo, del Consejo y de la Comisión, un dictamen motivado que exponga las razones por las que considera que el proyecto de acto legislativo (siempre en un plazo de ocho semanas a partir de la fecha de transmisión de éste) no se ajusta al principio de subsidiariedad; atribución que se correlaciona con el art. 3 , párr. $1^{\circ}$, del Protocolo sobre el cometido de los parlamentos nacionales en la Unión Europea (que por el TL también anexa). Por lo demás, el art. 7, del Protocolo sobre la aplicación de los principios de subsidiariedad y proporcionalidad diagrama las distintas alternativas procedimentales que seguirá la cuestión que tratamos, que esencialmente constituye el mecanismo de alerta rápida o temprana al que referiamos anteriormente.

D) Sucinto balance del accionar del Comité. Prospectiva

En cuanto al balance de la labor del Comité, existen criterios discordantes porque para algunos su injerencia real ha sido muy discreta y modesta; mientras que para otros, las regiones europeas han ganado en presencia activa en Europa a través del Comité, fundamentalmente, por medio de los informes que preceptivamente debe proporcionar al Consejo, la Comisión y el Parlamento en los temas vinculados a la politica regional.

7 Dicho Protocolo fue aprobado primigeniamente por el Tratado de Ámsterdam (1997). 
Sea como fuera, aunque perfectible, sin duda es un órgano con cierta trascendencia como instancia de articulación, contención y participación en el proceso comunitario europeo de las entidades que Pérez González denomina politico-territoriales ubicadas en un plano inmediato inferior al Estado (región en sentido estricto) y de otras entidades territoriales menores

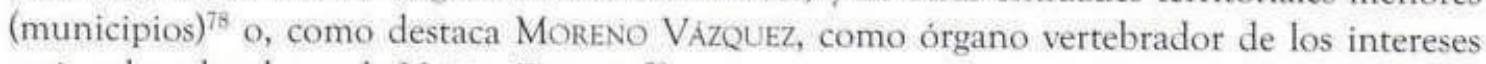
regionales y locales en la Unión Europea ${ }^{79}$.

Asimismo, se ha reivindicado su papel como facilitador o plataforma de intercambio entre las regiones, por ejemplo, en materia de clusters y desarrollo regional ${ }^{80}$. Cabe advertir que los clusters tienen por objetivo agrupar geográficamente a empresas y agentes del mismo sector: fabricantes, universidades, asociaciones, etc., para construir un polo de competitividad ${ }^{81}$.

El Comité es igualmente significativo desde el punto de vista simbólico, en tanto -como se anticipaba- encarna uno de los reflejos de la mutación del paradigma sobre la "cuestión regional" entre los tratados institutivos de las Comunidades Europeas, que la ignoraron, y el TUE que mostró su preocupación al respecto, canalizándola -entre otras manifestaciones que ya fueron colacionadas- en la instauración de aquel órgano preponderantemente consultivo.

Ya de cara al futuro, Delebarke -actual Presidente del Comité [fines de 2007]- ha identificado como un desafio importante la evolución institucional de la UE, recordando que el mandato conferido a la Conferencia Intergubernamental que cristalizara en el TL, "preserva lo esencial de los logros obtenidos por los entes territoriales en el proyecto de Tratado por el que se establece una Constitución para Europa, como el reconocimiento del respeto de la autonomia local y regional por la Unión, el mantenimiento del protocolo sobre la aplicación de los principios de subsidiariedad y proporcionalidad, la introducción de la cohesión territorial y la diversidad cultural y lingüistica entre los objetivos de la Unión"\$2.

\section{Eurocities}

Simplemente a modo ilustrativo, daremos aqui una brevisima noticia sobre "Eurocities",

75. Perez Gonzalez, Manuel, "Facultades de los entes subnacionales en el sistema comunitario eutopeo", en DrNas DE ClÉment, Zlata y REY CARO, Ernesto J. (Directores), Jomadas de reflexión sobre regionalización y Mercosur, cit., pp. 17 y 26.

79 Moreno VAzQuez, Manuel, op, cit., pp. 125 y ss.

so Cfr. Hnizdo, Petr, "Una oficina en Bruselas: algo más que una cuestión de prestigio...", en Regiones y Municipios de Europa, Boletin de información del Comité de las Regiones, $N^{\circ} 56$, verano de 2007, Bruselas, p. 9.

3i. Loc. cit. en nota anterior.

4: Delebarke, Michel, "Editorial", en Regiones y Municipios de Europa, Boletín de información del Comité de las Regiones, $\mathrm{N}^{\circ} 57$, octubre-diciembre de 2007, Bruselas, p. 2.

83 En torno a las actividades y al rol de Eurocities, ver para ampliar: www.eurocities.org/main.php. 
como instancia de vinculación y participación de las ciudades europeas en sectores temáticos de la politica comunitaria en los que están involucrados intereses comunes de aquéllas.

Se trata de una red de metrópolis europeas fundada en 1986 que reúne a los gobiernos locales de más de 130 ciudades importantes de alrededor de 30 paises europeos y cuyo objetivo primordial es constituirse en la voz de aquéllas en las instituciones comunitarias generando un espacio de diálogo sobre todos los aspectos de la normativa, politicas y programas de la UE que tengan impacto en las ciudades y sus ciudadanos.

Cabe acotar que actúa en una amplia gama de áreas temáticas, que incluyen: desarrollo económico y politica de cohesión; prestación de servicios pủblicos; medio ambiente; transporte; empleo y asuntos sociales; cultura, educación, información y sociedad de conocimiento; "gobernanza" y cooperación internacional.

Para encuadrar contextualmente su gestión, "Eurocities" percibe que Europa afronta una serie de grandes desafios que requieren una efectiva respuesta de parte de las autoridades públicas, entre las que se incluyen: asegurar la prosperidad económica y el desarrollo sustentable de ciudades y regiones; crear nuevas oportunidades de empleo; fortalecer la cohesion social y proteger el ambiente para las futuras generaciones. Entiende que tales desafios solo podrán ser adecuadamente encarados si los diferentes niveles de la administración pública (ciudades y regiones, gobiernos nacionales e instituciones europeas) trabajan conjuntamente.

Finalmente, $y$ a salvo las lógicas diferencias existentes entre ambos entes, podria trazarse un paralelismo entre "Eurocities" y "Mercociudades" (sobre la que volveremos), siendo esta última la principal red de municipios del Mercosur, creada en 1995, y que constituye un útil referente en el ámbito de protección de los intereses locales en dicho proceso integrativo sudamericano.

\section{ALTERNATIVAS DE PARTICIPACIÓN DE LOS ENTES SUBESTATALES EN EL PROCESO INTEGRATIVO MERCOSUREÑO}

Exploraremos sumariamente a continuación algunas posibilidades actuales y prospectivas de articulación y actuación en el ámbito del Mercosur que van despuntando o consolidándose para estados o provincias, regiones, municipios, departamentos y ciudades de sus Estados Miembros.

En esa dirección, haremos una breve alusión sucesivamente al Parlamento del Mercosur; al Foro Consultivo de Municipios, Estados Federados, Provincias y Departamentos del Mercosur y a la red denominada "Mercociudades". 
1. Sobre el Parlamento del Mercosur

Cabe destacar que el Protocolo Constitutivo del Parlamento del Mercosur (PCPM) fue suscripto por los presidentes de Argentina, Brasil, Paraguay y Uruguay el 9 de diciembre de 2005, a partir de la Decisión N²3/05 emanada de la XXIX Reunión del Consejo del Mercado Común $(\mathrm{CMC})^{84}$.

Dentro de la estructura institucional del Mercosur, el Parlamento-que reemplazó a la Comisión Parlamentaria Conjunta- es el órgano de representación de los pueblos de aquel, unicameral, independiente y autónomo (art. 1 del PCPM). Comenzó a funcionar el 7 de mayo de 2007.

El modo de elección de los "parlamentarios" 85 variará gradualmente de acuerdo con las siguientes pautas: a) en el actual estadio, los integrantes fueron elegidos de entre los miembros de los parlamentos nacionales; b) en una etapa posterior, desde 2011, serán elegidos por voto directo; y c) en la fase subsiguiente, a partir de 2015, además de voto directo, la elección será simultánea para garantizar la representatividad democrática ${ }^{86}$.

En realidad, tal determinación progresiva obedece a la interacción de los arts. 1 y 6 , incs, $1^{\circ}$ y $4^{\circ}$ y $1^{n}$ y $3^{n}$ Disposiciones Transitorias del PCPM.

Así, el art. 1, al tiempo de estipular que el Parlamento estará integrado por representantes electos por sufragio universal, directo y secreto, establece que "[l]a constitución del Parlamento se realizará a través de las etapas previstas en las Disposiciones Transitorias del presente Protocolo". Mientras tanto, el art. 6 , inc. $1^{\circ}$, pauta que aquella elección -con las características mencionadas- se realizará por los ciudadanos de los respectivos Estados Partes y el inc. $4^{\circ}$ de tal art. 6, determina que a propuesta del Parlamento, el CMC establecerá el "Dia del Mercosur Ciudadano" para la elección de los parlamentarios, de forma simultánea en todos los Estados Partes.

A su tiempo, la 1 $1^{\text {a }}$ Disposición Transitoria establece que, a los fines de lo previsto en aquel art. 1, se entenderá lo siguiente: por "primera etapa de transición", el periodo comprendido entre el 31 de diciembre de 2006 y el 31 de diciembre de 2010; y por "segunda etapa de transición", el periodo comprendido entre el 1 de enero de 2011 y el 31 de diciembre de 2014 . A su tiempo, la $3^{a}$ Disposición Transitoria determina que para la primera etapa de transición, los

44 Para consultar el texto de la Decisión y el Protocolo (como de otros instrumentos relevantes sobre el punto), véase Hacia el Parlamento del Mercosur. Una recopilación de documentos, 2a ed., Montevideo: Fundación Konrad Adenauer y Comisión Parlamentaria Conjunta del Mercosur (editores), 2006, pp. 21/32.

85 La denominación que reciben sus integrantes consta en el art. 5 , parr. $2^{\circ}$, del PCPM.

56. Tal información puede ubicarse en www.argentina.gov:ar/argentina/portal. 
parlamentos nacionales establecerán las modalidades de designación de sus respectivos parla. mentarios, entre los legisladores de los parlamentos nacionales de cada Estado Parte. Añade que, a los efectos de poner en práctica la elección directa de los parlamentarios (art. 6.1 del PCPM) antes de la finalización de la primera etapa de transición, deberán efectuar elecciones por sufragio directo, universal y secreto de parlamentarios, fijándose que la primera elección prevista en el art. 6 , inc. $4^{\circ}$, tendrá lugar durante 2014 . Finalmente, a partir de la segunda etapa de la transición todos los parlamentarios deberán haber sido elegidos de conformidad con el art. 6 , inc. $1^{\circ}$.

Entre los propósitos del Parlamento se cuentan los de asumir la promoción y la defensa permanentes de la democracia, la libertad y la paz; impulsar el desarrollo sustentable de la región con justicia social y respeto a la diversidad cultural de sus poblaciones, y garantizar la participación de los actores de la sociedad civil en el proceso de integración (art. 2, respectivamente, incs. $2^{\circ}, 3^{\circ}$ y $4^{\circ}$ ).

Por su parte, en el marco de los principios que postula la institución parlamentaria, pueden resaltarse, por ejemplo: el pluralismo y la tolerancia como garantias de la diversidad de expresiones políticas, sociales y culturales de los pueblos de la región; la cooperación con los demás órganos del Mercosur y ámbitos regionales de representación ciudadana; la promoción del desarrollo sustentable en el Mercosur y el trato especial y diferenciado para los países de economias menores y para las regiones con menor grado de desarrollo; y la equidad y la justicia en los asuntos regionales e internacionales (art. 3 , respectivamente, incs. $1^{\circ}, 3^{\circ}, 7^{\circ}$ y $8^{\circ}$ ).

Luego de bosquejar rápidamente algunos lineamientos del Parlamento mercosureño, es hora de acotar que, si logra consolidarse democráticamente, tal estructura puede constituirse también en una instancia de actuación y/o de control por parte de las entidades infraestatales de los paises miembros con estructura compleja en cuestiones que resulten de interés de aquéllas o que se vinculen a sus competencias especificas o concurrentes con el Estado Nacional de acuerdo con el reparto efectuado por las respectivas Constituciones.

En cuanto a la potencial utilidad que para los entes infranacionales puede ostentar la institución parlamentaria mercosureña, no debe olvidarse que en la parte considerativa de la nombrada Decisión CMC N²3/05, entre otros aspectos de interés, se dejó en claro que su instalación, "con una adecuada representación de los intereses de los ciudadanos de los Estados Partes, significará un aporte a la calidad y equilibrio institucional del Mercosur, creando un espa. cio comin en el que se refleje el pluralismo y las diversidades de la región, y que contribuya a la democracia, la participación, la representatividad, la transparencia y la legitimidad social en el desarrollo del proceso de integración y de sus normas" -énfasis agregado-(párr. $5^{\circ}$ ). 
Pensando prospectivamente, deberia existir -en palabras y hechos- un fluido diälogo y una franca cooperación entre el Parlamento del Mercosur y los Poderes Legislativos nacionales (fundamentalmente, en el caso de nuestro pais, a través de la Cámara de Senadores), para que entre otras cuestiones y supuesto el avance del esquema hacia etapas más intensas de relacionamiento, se preserven los principios de subsidiariedad y proporcionalidad, y puedan aquellos órganos nacionales comunicar fundadamente al Parlamento del Mercosur y al resto de las instituciones competentes, que en casos concretos existe el riesgo de que determinados proyectos normativos de la estructura integrativa vulneren la premisa de subsidiariedad, pues esta (en consonancia con la de proporcionalidad) supone una combinación de esfuerzos para "evitar la tendencia hacia el centralismo burocrático" 87 .

Es decir, ni más ni menos que una suerte de sistema de "alerta rápida o temprana", como el que en Europa prefigura el Tratado de Lisboa y que surge de la interrelación del texto que éste imprime al art. 3 ter, ap. 3 , in fine, del TUE, en cuanto a que los parlamentos nacionales velarán por el respeto del principio de subsidiariedad de acuerdo con el Protocolo sobre la aplicación de los principios de subsidiariedad y proporcionalidad, y art. 6 , párr. $1^{\circ}$, de este Protocolo, correlacionado con el art. 3 , párr. $1^{\circ}$, del Protocolo sobre el cometido de los parlamentos nacionales en la UE.

Según lo adelantado, el principio de subsidiariedad deberá engarzarse y funcionar armónicamente con el de proporcionalidad ${ }^{85}$ (y el de necesidad, con el que éste se asocia), por virtud del cual el contenido y la forma de la acción de la estructura comunitaria no excederán de lo necesario para alcanzar los objetivos del tratado constitutivo en cuestión ${ }^{89}$.

2. El Foro Consultivo de Municipios, Estados Federados, Provincias y Departamentos del Mercosur

Por medio de la Decisión No 41/04, de 16 de diciembre de 2004, el Consejo del Mercado Común, creó el Foro Consultivo de Municipios, Estados Federados, Provincias y Departamentos del Mercosur, que viene a suceder a la Reunión Especializada de Municipios e Intendencias.

La implementación del Foro constituye un importante logro de los entes locales, pues no es precisamente un dato menor que el órgano supremo del Mercosur y, como tal, conductor de la politica del proceso integrativo (el CMC), reconociera que el Foro que se creaba es útil

87 Cfr. Tratado de la Unión Europea [Textos consolidados de los Tratados Comunitarios], Secretaría de Estado para las Comunidades Europeas, notas a cargo de Losada GonzALEz, Herminio, Madrid, España, 1992, p. XXVII.

(24 Sobre el tema, y mutatis mutandi, ver LouIs, Jean-Victor, El ordenamiento juridico comunitario, 5 ed, correg. y actualiz., Luxemburgo: Comisión Europea, Oficina de Publicaciones Oficiales de las Comunidades Europeas, 1995, p. 105.

69. El concepto brindado en el texto sigue, en lo pertinente, el fijado por el art, 3 ter, ap. 4, párr. $1^{\circ}$, del TUE, según lo proyectado por el art. 1.6 del TL. 
para "estimular el diálogo y la cooperación entre las autoridades de nivel municipal, estadual, provincial y departamental de los Estados Partes del Mercosur" (art. 1).

Debe recordarse que el citado Foro, que serả integrado por representantes designados por los Estados Partes, de Municipios, Estados Federados, Provincias y Departamentos integrantes de sus respectivos territorios, podrá proponer medidas destinadas a la coordinación de politicas para promover el bienestar y mejorar la calidad de vida de los habitantes de tales entidades, asi como formular recomendaciones por intermedio del Grupo Mercado Común, es decir, del órgano ejecutivo del Mercosur.

Finalmente, no es sobreabundante computar que dentro de las estrategias de descentralización que en este caso conduzcan a la realización de actividades de alcance internacional por parte de los entes locales, ellas se desenvuelvan -como mutatis mutandi se puntualizara ${ }^{90}$ - en las siguientes áreas principales de acción: el llamado "hermanamiento" entre ciudades de diferentes países; la participación en organismos internacionales y en programas de cooperación internacional; $y$ la vinculación con embajadas y representaciones del exterior.

\section{Mercociudades}

Representa una instancia generadora de un espacio de vinculación y actuación de las entidades municipales en los marcos de integración internacional, presentándose además como la principal red de municipios del Mercosur y un referente destacado en los procesos de integración ${ }^{91}$.

Desde 1995, año de su fundación, ha venido bregando por "favorecer la participación de los municipios en el proceso de integración regional, promover la creación de un ámbito institucional para las ciudades en el seno del Mercosur y desarrollar el intercambio y la cooperación horizontal entre las municipalidades de la región", contando con ciudades asociadas de Argentina, Brasil, Paraguay, Uruguay, Venezuela, Chile, Bolivia y Perú ${ }^{92}$.

En otras palabras, el fundamento de su creación obedeció, por una parte y como se ha sostenido, a la necesidad de implementar un contexto institucional donde las ciudades pudieran expresar su opinión sobre el rumbo del proceso integrador y, por la otra, a desarrollar un terreno de convergencia e intercambio entre las ciudades, que permitiera desenvolver politicas más eficaces y adecuadas a los tiempos de la globalización ${ }^{93}$.

Cfr. Odoone, Nahuel y Granato, Leonardo, "Una integración diferente: el caso de Mercociudades", en Obsertatorio de la Economia Latinoamericana. Revista académica de Economia, No 38, febrero de 2005, ISSN 1696-8352; disponible en Internet en www.eumed.net/cursecon/ecolat $/ \mathrm{ar} / 2005 / \mathrm{cn}-\mathrm{lg} / \mathrm{texto}$.doc.

21 Ibid.

45 Cfr. ODdone, Nahuel y Granato, Leonardo, "Una integración diferente: el caso de Mercociudades", cit. en nota 90 . 
Ya en relación con los ambiciosos objetivos a los que propende, desplegados en el art. 2 de su Estatuto, pueden subrayarse -solo a titulo ejemplificativo- los siguientes: favorecer la participación de las ciudades en la estructura del Mercosur persiguiendo la co-decisión en las áreas de su competencia; impulsar la creación de redes de ciudades a través de unidades técnicas operativas que desarrollen diversas acciones, programas y proyectos de interés común intermunicipal adecuados al proceso de integración; coordinar la planificación y promover acciones vinculadas al crecimiento y al desarrollo urbano de las ciudades; colaborar en la planificación de las politicas y planes de desarrollo de las ciudades, tomando en cuenta la necesidad de mejorar la calidad de vida; impulsar la adopción de politicas que adecuen los proyectos locales al nuevo espacio regional; y difundir una cultura democrática y democratizadora en los niveles regional y nacional, estableciendo una relación más estrecha de cooperación para, a través de las municipalidades, definir politicas sociales adecuadas.

Para cerrar estas lineas debe advertirse que Mercociudades -que, como vimos y dejando a buen resguardo las diferencias entre ambos organismos, tiene cierta afinidad en cuanto a sus objetivos con "Eurocities" (red de metrópolis europeas)-, esencialmente reconoce como propósito institucional central lograr su reconocimiento en la estructura del Mercosur. Por lo pronto, su prédica para abrir un margen de participación de las ciudades en este, ha sido en cierta medida receptada primero con la creación de la Reunión Especializada de Municipios e Intendencias del Mercosur y luego con su sucesor, el aludido Foro Consultivo de Municipios, Estados Federados, Provincias y Departamentos del Mercosur.

\section{ESQUEMA DE CONCLUSIONES}

Como es de suponer, las anotaciones precedentes no presentan todos los aspectos conflictivos o interrogantes que se suscitan en la interrelación de dos procesos relevantes como la integración supranacional y el federalismo. En consecuencia, nos hemos limitado a enfocar algunos de sus puntos de contacto, tanto en la experiencia comunitaria europea como en la praxis integrativa del Mercosur en su etapa actual y su prefiguración prospectiva.

Del itinerario panorámico emprendido, pueden extraerse las siguientes observaciones finales, que vienen a añadirse a ciertas apreciaciones conclusivas ya intercaladas en otros segmentos de este trabajo:

1. No corresponde predicar a priori una incompatibilidad entre el proceso de integración supranacional, que contiene una importante nota de centralización, y el federalismo intraestatal, que supone un ejercicio de descentralización. Por el contrario, lo deseable seria generar una saludable complementación y armonización entre los elementos de esa relación binómica, a partir de claras normas contenidas cí la Constitución, que permitan al Estado involucrarse en 
prácticas comunitarias preservando paralelamente la pluralidad y las líneas centrifugas al interior del mismo, tema este último que también debería quedar literalizado entre los objetivos del tratado constitutivo en cuestión, al menos genéricamente como el respeto por las autonomias locales por parte de la estructura supranacional.

En otras palabras, concertar coherentemente el principio de "autonomia institucional" en la autoorganización del Estado, con el despliegue y la aplicación del derecho comunitario ad intra y la participación de los entes subestatales ad extra.

2. Como afirma GARCIA DE ENTERRIA, el respaldo que a todas las politicas vinculadas con la irrupción de los nuevos espacios económicos integrados, desde la Unión Europea al Mercosur y, más aún, la imposición real de una globalización de la economia que las nuevas técnicas hacen posible y las exigencias del desarrollo económico parecen imponer, prestan una perspectiva nueva y obligada a todo el movimiento de relocalización inexorable de los centros de decisión ${ }^{94}$.

3. En torno a la integración supranacional y su relacionamiento con las modalidades estaduales complejas, la referencia al paradigma europeo es inexcusable, porque, de una parte, aquel proceso lleva más de cinco décadas de desarrollo y, de la otra, se han incrementado intensamente Estados de estructura federal o regional, Estados regionalizados o experiencias de descentralización en naciones tradicionalmente unitarias.

Sin embargo, si bien cabe abrevar en una praxis tan avanzada como la de Europa, deben paralelamente evitarse los implantes juridicos artificiales, sorteando "las distorsiones y los espejismos" ${ }^{95}$ de la visión iuscomparada. Dicho en otros términos, cabe tener presente la utilidad que aporta la observación de las vivencias extranjeras como matriz para el posterior examen comparativo, pero sin perder de vista que lo apropiado es extraer de tal operación solo lo aplicable a la cultura, la idiosincrasia y la realidad juridicas, donde el plexo normativo proyectado esté llamado a operar, pues especificamente en el caso del federalismo (o de los federalismos, en la visión de FrIEDRICH), al tiempo de ser un proceso complejo y dinámico, cada contexto nacional y local tiene particularidades intransferibles.

El resultado de la indagación, por tanto, no puede ser sino con beneficio de inventario, extrapolando lo que se revele consistente con la arquitectura y la ideologia juridicas del sistema en el que se pretendan aplicar aquellas experiencias y evitar, asi, artificiales mimetismos. ciỏn: rol de las regiones, provincias y municipios, cit., p. XV.

95 La gráfica expresión es de LOPEz GUERRA, Luis, "Estudio preliminar", en Las sentencias básicas del Tribunal Constitucional, Madrid: Centro de Estudios Politicos y Constitucionales, Boletin Oficial del Estado, 2000, p. 31 . 
4. En el ámbito del Mercosur, y partiendo de la base de que existiera verdadera voluntad politica de construir progresivamente una estructura supranacional más avanzada y demandante, los paises componentes del modelo deberian acometer una compatibilización constitucional pues desde un prisma iuscomparado se observan ostensibles asimetrias.

Insistimos en la necesidad de que medie sincero empeño politico ya que ni la elaboración de normas ni la creación de instituciones tienen efectos taumatúrgicos. Por ende, nada solucionarán o modificarán si no las mueve una sincera decisión estratégica de asumir compromisos más sólidos en el marco integrativo.

Lo ideal seria que las respectivas Leyes Fundamentales contengan normas que claramente pauten el valor que frente al derecho interno tendrán los instrumentos internacionales y que prefiguren una cláusula de habilitación para la cesión, atribución, traspaso, delegación o transferencia de competencias a entes supranacionales, paralelamente a un acondicionamiento jurisprudencial, para que la potencial arquitectura institucional que se genere no se derrumbe por falta de consistencia juridica.

Recuérdese que el derecho comunitario presenta como lineas fisonómicas especificas la autonomia y el efecto directo e inmediato de sus normas, caracteristicas que conducen a su aplicación preferente sobre el ordenamiento juridico interno de los Estados que componen el espacio regional en cuestión.

Del recorrido comparativo realizado, surge que las configuraciones constitucionales de Argentina y Paraguay se encuentran suficientemente preparadas sobre el particular, al igual que Venezuela (si hipotéticamente se lo incluyera en la nómina sobre la base de su pretendida incorporación plena a las filas del Mercosur); no asi las de Brasil y Uruguay, acercà de las cuales calificada doctrina postula la necesidad de llevar adelante sendas reformas constitucionales para legitimar la creación de organizaciones supranacionales recipiendarias de competencias o atribuciones dispensadas por tales Estados Miembros, al tiempo de requerirse -para completar el acondicionamiento conveniente- un correlativo acompañamiento jurisprudencial de los respectivos órganos de cierre de la jurisdicción constitucional, es decir, el Supremo Tribunal Federal brasileño y la Suprema Corte de Justicia uruguaya.

5. Si se lograra salvar la asimetria juridica y contar con la voluntad politica necesaria, abriendo paso a estructuras integrativas más complejas y exigentes (sin diluir las identidades nacionales), entre otros aspectos relevantes que surgen de la interacción del espacio supranacional y el federalismo, cabria prestar especial atención al impacto que el proceso integrativo pudiera provocar en las entidades infraestatales y canalizar las energias para concebir cauces idóneos que permitan a éstas participar de dich experiencia. 
Ello deberia cristalizarse en algunas de las fases, ascendente o de celebración de los tratados internacionales que pueden afectar los ámbitos competencial o de intereses de tales entes locales, o descendente o de aplicación de la normativa comunitaria en el escenario intranacional; asimismo, seria aconsejable viabilizar la vinculación de estos con sus pares del mismo Estado o de otros, para ganar peso especifico y hacer oir sus reclamos en el área integrada.

En otras palabras, y aunque suene reiterativo, se impone la necesidad de consolidar un diálogo en dos frentes: el comunitario, permitiendo a las instancias subestatales en cuestión comunicarse con las instituciones de la estructura supranacional; y el intraestatal, generando una coordinación entre los gobiernos centrales y los locales en lo que atañe al proceso de integración.

6. Las actividades que en la órbita internacional pueden desplegar estados y provincias (y, ¿por qué no?, también municipios, aunque estos con un doble orden de limitacioon: las constituciones nacional y provincial o estadual que correspondan), se entienden a partir de una relectura de la concepción clásica de relaciones internacionales, separando el núcleo duro de estas, reservado al poder central, del nuicleo blando, que pueden llevar adelante los entes subnacionales respetando el principio de "lealtad constitucional".

7. Ligado a ello, Hernández plantea con acierto que la integración regional importa lagregamos por nuestra cuenta: principalmentel dos desafios fundamentales para las provincias: de un lado, alcanzar los objetivos del desarrollo económico y social y del desarrollo humano, con la magnitud de los cambios politicos, económicos, educativos, culturales y sociales por afrontar, comenzando con una tarea de compatibilización de la legislación; $y$, por otro, cumplir con las obligaciones inherentes a la integración supranacional, como parte de un Estado Miembro del Mercosur $^{96}$.

Ya en un plano general (esto es, que involucra no sólo a nuestro pais), en la dimensión interna los retos esbozados deberian tener como matriz legitimante un federalismo de concertación y participativo, que permita una relación equilibrada entre las instancias que componen la estructura federal (Nación, Estados o provincias; municipios, departamentos; etc,, de acuerdo con la terminologia empleada constitucionalmente por cada pais) y posibilite un proceso integrado de crecimiento y evolución ad extra y ad intra ${ }^{97}$.

\footnotetext{
HERNÁNDEZ (h.). Antonio Maria, Integración y globalización: rol de las regiones, provincias y mutnicipios, cit., p. 60 .

Sobre el particular, ver BARON KNOLl DE BertolotTr, Silvina, "La provincia en los procesos de integración. Relaciones del Estado Nacional y las provincias con el Mercosur". Derecho público provincial y municipal, Vol. 1, cit., pp. 181/199.
} 
No menos importante es que tal esquema equilibrado se traslade a la propia estructura comunitaria y su sistema distributivo y de ejercicio de competencias con cada uno de los Estados Miembros, preservando los patrones de atribución, subsidiariedad, proporcionalidad ${ }^{95}$ y necesidad, o sea, respectivamente: a) que la estructura comunitaria actúe dentro de los limites de las competencias que le atribuyen los Estados en los tratados institutivos para lograr los objetivos que éstos determinan, pautándose que toda competencia no atribuida a ella corresponderá a los Estados Miembros; b) que las decisiones politicas se adopten en el contexto más cercano al ciudadano para obtener el mayor grado de eficacia posible, por lo que el ente comunitario, en los ámbitos que no sean de su competencia exclusiva, intervendrá solo en caso y en la medida de que los objetivos de la acción pretendida no puedan ser alcanzados de manera suficiente por los Estados Miembros, ni en el nivel central ni en los niveles regional o local; y c) por virtud del tercero y el cuarto principios, que el contenido y la forma de la acción de la entidad comunitaria no excedan de lo necesario para alcanzar los objetivos del tratado constitutivo.

8. En el marco de análisis del derecho comparado, y dentro de los anunciados limites, habria que tener presente la praxis del Comité de las Regiones en Europa (para la eventual extrapolación de algunas de sus pautas ante una hipotética vinculación comunitaria más intensa que la que hoy caracteriza al Mercosur), órgano que resulta útil como instancia de articulación, contención y participación de las entidades subestatales en el proceso comunitario europeo; estructura armonizadora de los intereses regionales y locales; $y$ matriz facilitadora de intercambios regionales para el desarrollo de aquéllas.

La principal labor del Comité gira al compás de su rol consultivo, fundamentalmente en el plano de los dictámenes preceptivos que brinda al Consejo, la Comisión y el Parlamento y los que motu proprio puede realizar. Ya en cuanto a la esfera politica, su actividad se orienta a allanar la aplicación de los principios de subsidiariedad y proporcionalidad en la Unión Europea.

Por último, el Tratado de Lisboa -que esencialmente modifica al TUE y al Tratado Constitutivo de la Comunidad Europea (que pasará a denominarse Tratado de Funcionamiento de la UE) y cuya ratificación se espera sea concluida antes del 31 de diciembre de 2008 para que entre en vigor de cara a las elecciones al Parlamento Europeo de junio de 2009-, consagra ciertas premisas relevantes para los entes territoriales, por ejemplo: la inclusión de la denominada "cohesión territorial" (paralelamente a la cohesión económica y social) como finalidad de la Unión; el reconocimiento del respeto por parte de ésta de la autonomia local y regional; y el mantenimiento del protocolo sobre la aplicación de los principios de subsidiariedad y

95. Ver sobre el punto, el art. 1.6 del TL, que introduce el art. 3 ter del TUE, fuente de la que se han extraido algunas pautas para perfilar los principios de atribución (al que también se refiere el art. 1.5 del TL, que deroga el art. 3 e incorpora el art. 3 bis del TUE), subsidiariedad y proporcionalidad volcadas en el texto. 
proporcionalidad, reconociéndosele legitimación al Comité de las Regiones para interponer recursos ante el Tribunal de Justicia de la Unión por violación al principio de subsidiariedad, órgano aquel que también recepta habilitación para actuar ante dicho Tribunal en defensa de sus prerrogativas.

9. Algunas posibilidades actuales y prospectivas de articulación y actuación en el dominio del Mercosur que van apareciendo o afianzándose para estados o provincias; regiones; municipios, departamentos y ciudades, pueden localizarse en el Parlamento del Mercosur; el Foro Consultivo de Municipios, Estados Federados, Provincias y Departamentos del Mercosur, y la red denominada "Mercociudades", especificamente para ciudades y municipios.

En lo tocante al Parlamento del Mercosur, una vez que se consolide, debería mantener un constante y fluido diálogo con los Poderes Legislativos nacionales (principalmente en el caso argentino a través de la Cámara de Senadores, que deberá revitalizarse y asumir cabalmente su rol como interlocutora y defensora de los intereses provinciales), para que entre otras cuestiones y supuesto el avance del esquema hacia etapas más intensas de relacionamiento, se preserven los principios de subsidiariedad y proporcionalidad, y puedan aquellos órganos nacionales comunicar fundadamente al Parlamento mercosureño y al resto de las instituciones competentes, que en casos concretos existe el riesgo de que determinados proyectos normativos de la estructura integrativa vulneren la premisa de subsidiariedad, que en retroalimentación con la de proporcionalidad coadyuva a mitigar la tendencia centralista del proceso de integración.

Por su parte, tanto el Foro Consultivo de Municipios, Estados Federados, Provincias y Departamentos en el ámbito del Mercosur, como la red "Mercociudades" -por supuesto, cada uno de ellos conforme a sus posibilidades materiales y esferas competenciales-, constituyen iniciativas plausibles para lograr cauces de vinculación y participación de las entidades subestatales en el proceso mercosureño, y espacios para facilitar la cooperación horizontal entre ellas y con miras a un desarrollo más equilibrado que disminuya las disparidades y los desequilibrios económicos, sociales y territoriales.

10. En punto a la intervención de las colectividades territoriales en la denominada fase ascendente, podrian por ejemplo y mutatis mutandi, tenerse en cuenta la experiencia alemana (también contenida en la Constitución austríaca) que prefigura la actuación de los Länder en la etapa de celebración de los tratados internacionales que pueden afectar su competencia o intereses; y la figura del Ländersbeobachter, u observadores de los Länder, que toma parte como miembro de la delegación alemana al Consejo de Ministros de las sesiones que aborden temas que afecten a los Länder. 
Ya en relación con la fase descendente de aplicación y desarrollo del derecho comunitario derivado dentro del Estado, por varias razones se abren distintas perspectivas para las entidades subnacionales. Asi, ilustrativamente, cabria recordar un dato fáctico que marca que la mayor parte de la normativa comunitaria se ejecuta en estas, con lo cual, es particularmente relevante su intervención en la correspondiente etapa aplicativa. De su lado, y con no menor trascendencia, aparece otro aspecto de la cuestión y que estriba en que en el plano comunitario las "directivas" fijan lineamientos generales dejando sitio para su desarrollo ulterior por parte de las instancias estatales internas, área en la que puede germinar una via cierta de participación de los entes locales en equilibrada coordinación con los Estados Nacionales.

Ciertamente, y de su lado, la actuación de los niveles infraestatales en los procesos de adopción de decisiones en la estructura comunitaria sobre materias de competencia de aquellos o susceptibles de afectar sus intereses, puede ser: directa, mediante la presencia de representantes en las instituciones u órganos de esta; e indirecta, por medio de diversos mecanismos internos para influir en la posición que ante la órbita supranacional adopte el Estado al que pertenecen.

11. Para terminar, $y$ aunque aparezca desconectado del tema central que abordamos en el presente trabajo, nos permitimos mencionar que cualquiera fuera la decisión que se tomara para gobernar el futuro del Mercosur, en este -como en cualquier proceso de integración-será siempre relevante todo cuanto se haga para compatibilizar eficiencia técnica con democracia ${ }^{99}$, en orden a procurar la convergencia de una modulación no traumática de las relaciones que genera la tensión mercado, por una parte, y democracia y derechos humanos, por la otra.

Insistimos en la necesidad de no obviar la dimensión humanista de los fenómenos integrativos, pues en paráfrasis de MONNET -ideólogo de la integración europea-, con la comunitariedad no se persigue la mera coalición de Estados, sino la unión de hombres ${ }^{100}$, debiendo desterrarse la percepción que indica que la perspectiva crematistica es la única válida y posible para visualizar los procesos de integración.

Asi, derechos humanos y democracia son recaudos juridica y axiológicamente imprescindibles en cualquier intento serio de integración supranacional, y sustento esencial de su legitimidad $^{10 !}$.

Cruro Caldan, Miguel Ángel, El Derecho Universal. Perspectita para la ciencia juridica de una nueva era, Rosario: Fundación para las Investigaciones Juridicas, 2001, p. 95.

100 La frase textual es: "No coaligamos Estados, unimos hombres"; aludida por OREJA AGUIRRE, Marcelino, en VEGA MóoroA, Isabel (coordinadora), La integración económica europea, Prólogo, Lex Nova, Valladolid, 1996, p. 15.

101 Ver BazAN, Victor, por ejemplo, en "El Mercosur en prospectiva: la dimensión constitucional del proceso integrativo. La opción axiológica en favor de la seguridad juridica comunitaria y de la protección de los derechos fundamentales", El Derecho, 10 de diciembre de 1998, Buenos Aires, pp. 10/16. 
Finalmente, y como enseña FRLAs, la integración evitará que quedemos más solos en un mundo más unido, pero la integración es el reconocimiento de la interdependencia de los pueblos y personas, con su propia identidad ${ }^{102}$; premisa irrecusable si verdaderamente se desea transitar con provecho los nuevos senderos del federalismo ${ }^{103}$ en los pliegues del proceso comunitario.

102 FriAs, Pedro. J., "Las responsabilidades morales y políticas", Los Breviarios del Siglo XXI, Córdoba, sin fecha de edición.

103 La frase que cierra el trabajo está obviamente tomada del titulo de la obra de LA PERGoLA, Antonio, Los nuevos senderos del federalismo, Madrid: Centro de Estudios Constitucionales, 1994. 
